"Operation Modes for the Electric Vehicle in Smart Grids and Smart Homes: Present and Proposed Modes"

IEEE Transactions on Vehicular Technology, vol.65, no.3, pp.1007-1020, Mar. 2016.

http://ieeexplore.ieee.org/xpl/articleDetails.jsp?reload=true\&arnumber=7273953

ISSN: 0018-9545

DOI 10.1109/TVT.2015.2481005

This material is posted here with permission of the IEEE. Such permission of the IEEE does not in any way imply IEEE endorsement of any of Group of Energy and Power Electronics, University of Minho, products or services. Internal or personal use of this material is permitted. However, permission to reprint/republish this material for advertising or promotional purposes or for creating new collective works for resale or redistribution must be obtained from the IEEE by writing to pubs-permissions@ieee.org. By choosing to view this document, you agree to all provisions of the copyright laws protecting it. 


\title{
Operation Modes for the Electric Vehicle in Smart Grids and Smart Homes: Present and Proposed Modes
}

\author{
Vítor Monteiro, Student Member, IEEE, \\ J. G. Pinto, Student Member, IEEE, and João L. Afonso, Member, IEEE
}

\begin{abstract}
This paper presents the main operation modes for an electric vehicle (EV) battery charger framed in smart grids and smart homes, i.e., are discussed the present-day and are proposed new operation modes that can represent an asset towards EV adoption. Besides the well-known grid to vehicle (G2V) and vehicle to grid (V2G), this paper proposes two new operation modes: Home-to-vehicle $(\mathrm{H} 2 \mathrm{~V})$, where the $\mathrm{EV}$ battery charger current is controlled according to the current consumption of the electrical appliances of the home (this operation mode is combined with the G2V and V2G); Vehicle-for-grid (V4G), where the EV battery charger is used for compensating current harmonics or reactive power, simultaneously with the G2V and V2G operation modes. The vehicle-to-home (V2H) operation mode, where the EV can operate as a power source in isolated systems or as an off-line uninterruptible power supply to feed priority appliances of the home during power outages of the electrical grid is presented in this paper framed with the other operation modes. These five operation modes were validated through experimental results using a developed $3.6 \mathrm{~kW}$ bidirectional EV battery charger prototype, which was specially designed for these operation modes. The paper describes the developed EV battery charger prototype, detailing the power theory and the voltage and current control strategies used in the control system. The paper presents experimental results for the various operation modes, both in steady-state and during transients.
\end{abstract}

Index Terms - Bidirectional Battery Charger, Electric Vehicle, G2V - Grid-to-Vehicle, H2V - Home-to-Vehicle, Smart Grids, Smart Homes, V2G - Vehicle-to-Grid, V4G Vehicle-for-Grid, V2H - Vehicle-to-Home.

\section{INTRODUCTION}

$\mathrm{T}$ HE electric mobility represents a new paradigm of transport for the society, resulting in a more efficient and sustainable mobility [1][2]. Consequently, it is also an asset for the independence of oil costs and to reduce the greenhouse

"Copyright (c) 2015 IEEE. Personal use of this material is permitted. However, permission to use this material for any other purposes must be obtained from the IEEE by sending a request to pubs-permissions@ieee.org. "

This work has been supported by FCT - Fundação para a Ciência e Tecnologia in the scope of the project: PEst-UID/CEC/00319/2013. Mr. Vítor Monteiro was supported by the doctoral scholarship SFRH/BD/80155/2011 granted by the FCT agency.

Vítor Monteiro, J. G. Pinto, and João L. Afonso are with Centro Algoritmi, University of Minho, Dept. Industrial Electronics, 4800-058 Guimarães, Portugal; emails: vmonteiro@dei.uminho.pt, gpinto@dei.uminho.pt and jla@dei.uminho.pt. gas emissions [3]. This new paradigm of transport is mainly supported by the electric vehicle (EV) [4][5], where the batteries are charged from the power grid through on-board or off-board chargers [6][7], through integrated battery chargers [8], or even through inductive chargers, i.e., contactless charging systems [9]. In this context, also a reconfigurable on-board EV battery charger with the capability to charge the auxiliary battery from the traction batteries (traction-to-auxiliary operation mode) is proposed in [10]. Nevertheless, the power grids were not designed to support this new electrical appliance, where the power quality and the power grid stability are the main issues derived from the uncontrolled EV battery charging process [11][12]. Moreover, the full adoption of EVs is strongly dependent of major technological issues related with the energy efficiency and the innovation in energy storage systems [13][14]. Nowadays, with the introduction of EVs in the power grids around the world [15][16], new research challenges are emerging in terms of open electricity markets, and for the advancing in the production and integration of renewable energy [17][18]. An integrated energy management system to incorporate EVs in power grids with intermittent production of energy from renewables is proposed in [19]. In this context, a complex scheme for the charging scheduling of EVs considering their uncertain arrival and different energy prices is proposed in [20].

With the integration of EVs, where the batteries are charged from the power grid, arises the concept grid-to-vehicle (G2V). However, due to the capacity of the EVs to store energy, using bidirectional battery chargers, it is possible to send energy in the opposite way, i.e., from the EV batteries to the power grid. This operation mode is well documented in the literature and is identified as vehicle-to-grid (V2G) [21][22]. The V2G operation mode can also be used to stabilize the power grid and to support large-scale renewable energy integration as presented in [23]. Therefore, the EV can operate as active element in collaboration with the power grids [24]. Nevertheless, since the EV batteries are charged and discharged, a cost function should be modeled for the V2G operation mode [25]. In this context, the EV can be used as an active element in the power grid, i.e., it can operate as an energy storage system (enabling consumption, storage and also return of energy back to the power grid), and 
consequently contributing for the power grid stabilization [23]. For such purpose, the design of an aggregator of EVs is presented in [26].

The G2V and V2G operation modes are controlled to share active power with the power grid, neglecting the other electrical appliances of the electrical installation where the EV is plugged. This is a drawback, mainly, when the EVs batteries are charged at home. Therefore, one of the innovative operation modes proposed in this paper consists of a smart charging strategy for the EVs, targeting the future smart homes. This strategy consists of regulating the current in the $\mathrm{EV}$ as a function of the total current in the home, aiming to prevent overloads and overcurrent trips in the main circuit breaker [27]. This smart strategy for the EV battery charging can be used in both G2V and V2G operation modes and is defined in this paper as home-to-vehicle $(\mathrm{H} 2 \mathrm{~V})$.

Besides the present $\mathrm{G} 2 \mathrm{~V}$ and $\mathrm{V} 2 \mathrm{G}$ operation modes, where active power is exchanged between the EV and the power grid, the EVs can also be used to produce reactive power. As example, in [28] and [29] are presented two studies showing that the EV battery charger is capable to produce reactive power simultaneously with the $\mathrm{G} 2 \mathrm{~V}$ and $\mathrm{V} 2 \mathrm{G}$ operation modes. In the scope of the study presented in [28], this operation mode ( $\mathrm{EV}$ battery charger producing reactive power) is assessed in more detail in [30], where are considered five distinct operation modes (normal G2V, G2V with production of capacitive reactive power, $\mathrm{G} 2 \mathrm{~V}$ with production of inductive reactive power, only production of capacitive reactive power, and only production of inductive reactive power). In this operation mode, proposed in this paper as vehicle-for-grid (V4G), besides producing reactive power, the EV battery charger can also implement active power filter functionalities, i.e., compensating current harmonics produced by the home nonlinear electrical appliances. A great advantage of this operation mode is that it does not use the EV batteries, and therefore it does not cause their aging. Moreover, according with the nominal power of the EV battery charger, this operation mode can be used simultaneously with the G2V or V2G operation modes. This operation mode (V4G) will represent an asset to the smart grids if the EV is kept plugged to the power grid even when it is not in charging. Taking into account that the EV is a dynamic load for the power grid, it can be used in this operation mode in public or private EV charging stations. This interactivity between the EVs and the smart grids will demand efforts towards the development of smart homes [31], facilitating the implementation of efficient energy management solutions [32][33]. As example, the integration of the EV in smart homes is presented in [34].

Besides the aforementioned operation modes $(\mathrm{G} 2 \mathrm{~V}, \mathrm{~V} 2 \mathrm{G}$, $\mathrm{H} 2 \mathrm{~V}$, and $\mathrm{V} 4 \mathrm{G}$ ), using a bidirectional EV battery charger based in a voltage-source converter, the EV can also be used to operate as voltage-source. The vehicle-to-home (V2H) operation mode was initially proposed in [35] and was enhanced in [7]. However, in both cases are only presented the preliminary results of this operation mode, i.e., it was only validated with linear electrical appliances. Therefore, in the scope of this paper this operation mode was improved and validated with nonlinear electrical appliances, which is a more realistic condition. This operation mode (V2H) can be separated in two cases: when the EV is used as a voltage-source in isolated systems, and when the EV is used to operate as an off-line uninterruptible power supply (UPS), in grid-connected mode. Nevertheless, taking into account that this operation mode requires energy from the EV batteries, it must be managed in accordance with the $\mathrm{EV}$ driver convenience.

Considering the operation modes of the present-day $(\mathrm{G} 2 \mathrm{~V}$ and $\mathrm{V} 2 \mathrm{G}$ ) and the proposed operation modes, the EV can operate as a versatile active element, capable of consuming, storing, and providing energy. The interactivity between the aforementioned operation modes with the power grid must be controlled in order to bring benefits for the power grid and for the EV driver. Therefore, the information and communication technologies for smart grids will play an important role [36]. As example, in [37] is presented a mobile information system, denominated vehicle-to-anything (V2A), which is used to give relevant information to the EV driver, for instance, recommendations to manage the range autonomy, information about the electricity market, location of EV, location of public EV battery charging stations, and daily route planner.

Along this paper are presented experimental results obtained with a developed on-board EV battery charger prototype under real conditions to validate the presented and proposed operation modes: (1) the G2V operation mode; (2) the V2G operation mode; (3) the H2V operation mode; (4) the V4G operation mode; and (5) the V2H operation mode. During the five operation modes it is used the same EV battery charger and the main control algorithm is divided in five algorithms (each one for each operation mode). These five operation modes are analyzed independently and in detail from the section III to the section VII.

The rest of this paper is organized as follows. Section II presents the developed EV battery charger prototype used in the experimental tests, i.e., the power electronics description and the digital controller design. The G2V and V2G operation modes are presented, respectively, in sections III and IV. The $\mathrm{H} 2 \mathrm{~V}$ operation mode is presented in section V. The V4G operation mode, i.e., when the EV battery charger is used to compensate harmonics and reactive power, is presented in section VI. Section VII presents the V2H operation mode with the EV operating in two distinct cases: as a voltage-source in isolated systems and as an off-line UPS. Finally, section VIII presents the main conclusions of this work.

\section{DEVElOPED BiDiRECTIONAL ON-BOARD EV BATTERY CHARGER}

Fig. 1 shows the EV integration in the power grids and the on-board EV battery charger used to validate the different operation modes. Fig. 1(a) shows the power converter topology. Fig. 1(b) shows the hardware of the on-board EV battery charger prototype.

\section{A. Power Electronics Description}

The developed on-board EV battery charger has a nominal 


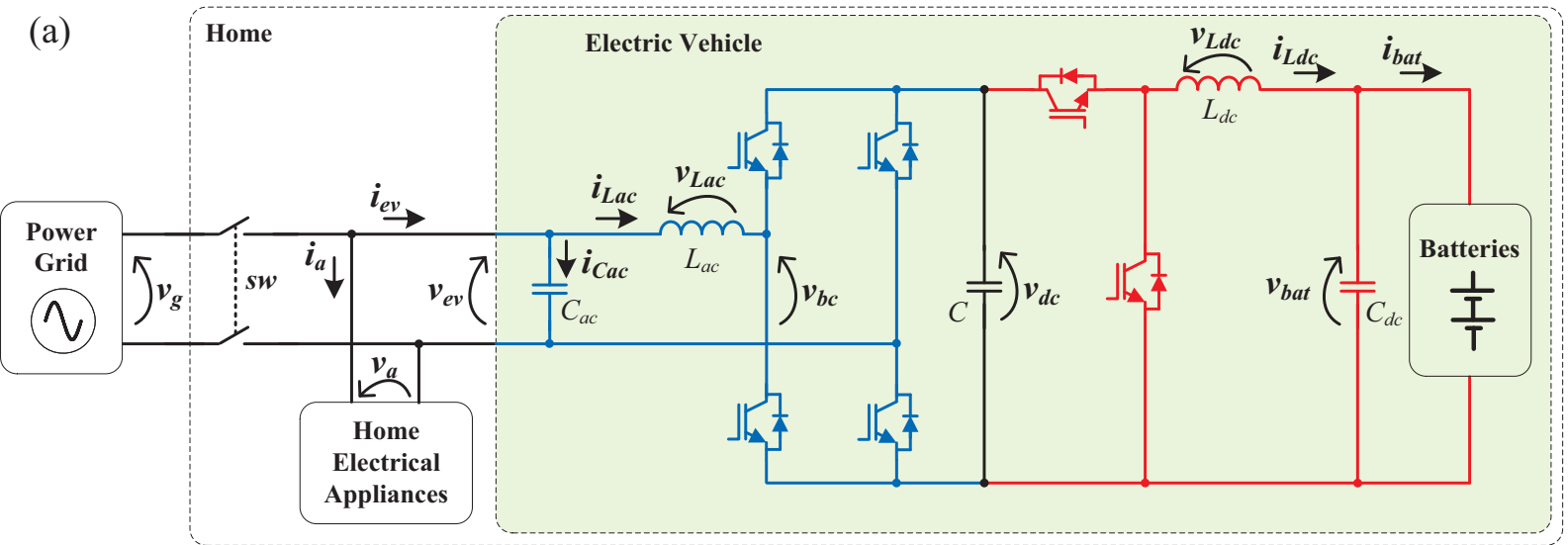

(b)

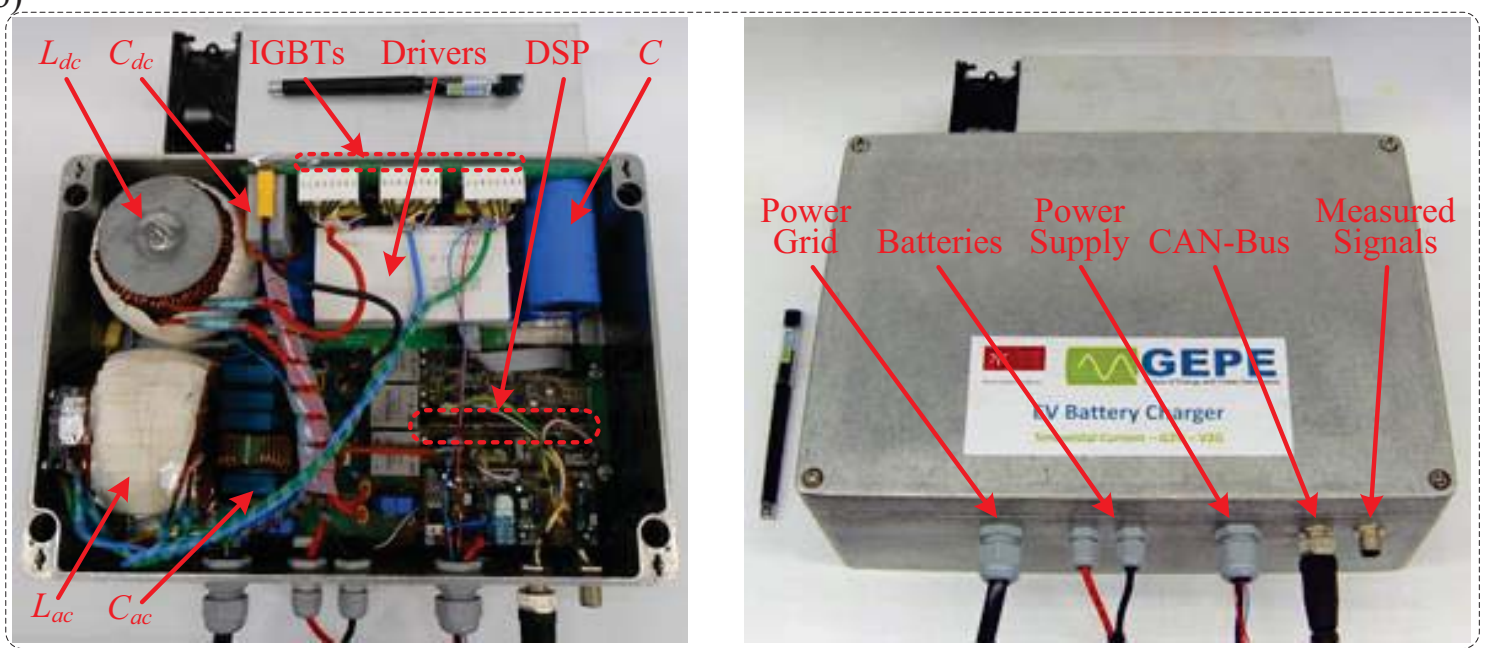

Fig. 1. Developed EV battery charger used to validate the proposed operation modes: (a) Power converter topology; (b) Hardware of the EV battery charger.

power of $3.6 \mathrm{~kW}$ and is composed by two power converters (cf. Fig. 1(a)) with a total power density of $0.43 \mathrm{~kW} /$ liter and an efficiency of $94 \%$ during the $\mathrm{G} 2 \mathrm{~V}$ (which is the main operation mode) at the rated power of $3.6 \mathrm{~kW}$. The ac-dc front-end converter is used to interface the power grid, i.e., it is a bidirectional voltage-source converter controlled by current (or voltage according with the operation mode). This converter was designed to be connected to the power grid with a nominal voltage of $230 \mathrm{~V}$, i.e., for a maximum rms current about of $16 \mathrm{~A}$. The dc-dc back-end converter is used to interface the batteries, i.e., it is a dc-dc half-bridge bidirectional converter controlled by voltage or current. This converter was designed for a maximum output current of $10 \mathrm{~A}$ and a voltage range between $250 \mathrm{~V}$ and $400 \mathrm{~V}$. In both power converters IGBTs are used (model IXXR110N65B4H1) from the manufacturer IXYS, which are switched at $20 \mathrm{kHz}$. The IGBTs use drivers SKHI61R from the manufacturer Semikron. In parallel with each leg a snubber capacitor of $1 \mu \mathrm{F}(1000 \mathrm{~V})$ is used. The voltages and currents are measured with hall-effect sensors, respectively, CYHVS5-25A and LTSR15-NP. The input inductor $\left(L_{a c}\right)$ has a value of $5 \mathrm{mH}$ $(20 \mathrm{~A})$, the input capacitor $\left(C_{a c}\right)$ has a value of $5 \mu \mathrm{F}(400 \mathrm{~V})$, the dc-link capacitor $(C)$ has a value of $3 \mathrm{mF}(450 \mathrm{~V})$, the output inductor $\left(L_{d c}\right)$ has a value of $2 \mathrm{mH}(12 \mathrm{~A})$, and the output capacitor $\left(C_{d c}\right)$ has a value of $680 \mu \mathrm{F}(400 \mathrm{~V})$. These passive components were selected in order to design a reliable on-board EV battery charger, according to the requirements of the project "MobiCar - Design, development, testing and demonstration of sustainable mobility solutions" - PPS 4: "MOBICar.Power - Development of powertrain architectures for electrical systems", leaded by the company CEiiA [38]. In this project we were responsible for the development of a compact and highly efficient on-board bidirectional battery charger, with sinusoidal current at the power grid side, for operation in $\mathrm{G} 2 \mathrm{~V}$ and $\mathrm{V} 2 \mathrm{G}$ modes.

\section{B. Digital Controller Design}

The current and voltage control strategies for both ac-dc and dc-dc converters are presented in this item. The digital control is implemented in a DSP (model TMS320F28335) from Texas Instruments. In order to obtain sinusoidal references to the grid current (or to the voltage during the $\mathrm{V} 2 \mathrm{H}$ operation mode) is used a phase-locked loop (PLL) algorithm according to [39]. This PLL algorithm provides two unitary signals in phase $\left(p l l_{s}\right)$ and in quadrature $\left(\mathrm{pll}_{c}\right)$ with the power grid fundamental voltage. It is important to refer that the power theory that allows obtain the references for the current (or voltage) is described for each operation mode in the next sections (cf. section III to section VII). Fig. 2 shows the flowchart of the digital control system. According with this 


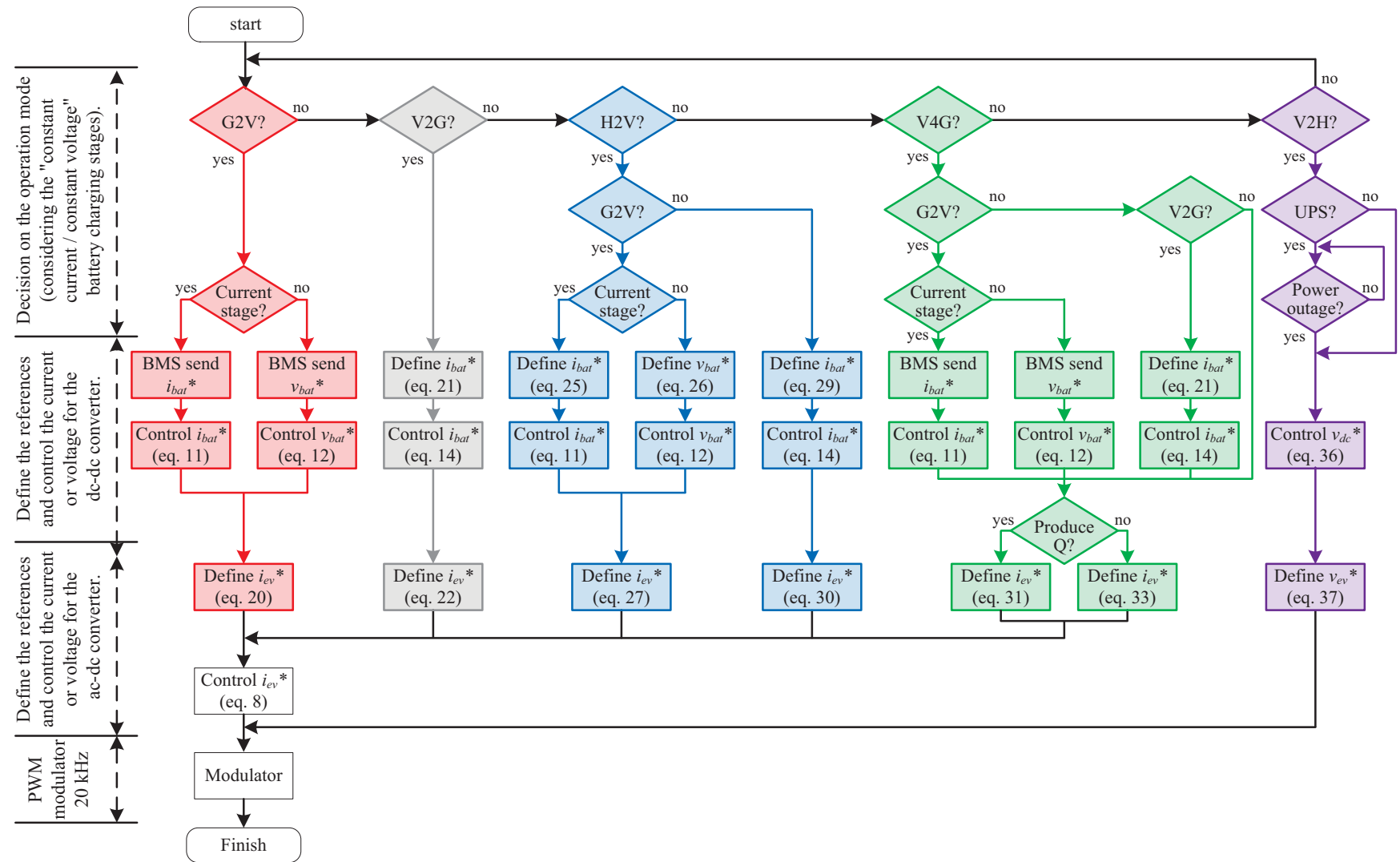

Fig. 2. Flowchart of the digital control system.

architecture, in the next sections are presented in detail the control strategies for each operation mode.

\section{1) Ac-Dc Front-End Converter}

From Fig. 1(a), analyzing the voltages and currents between the power grid and the EV battery charger, it can be established that:

$i_{e v}=i_{C a c}+i_{L a c}$,

$v_{g}=v_{\text {Lac }}+v_{b c}$.

Substituting the current in the capacitor $\left(i_{C a c}\right)$ represented in (1) it can be established:

$i_{e v}=C_{a c} \frac{d v_{C a c}}{d t}+i_{\text {Lac }}$.

Substituting (3) in (2) and rearranging in order to the voltage $\left(v_{b c}\right)$ that the EV battery charger must produce is obtained:

$v_{b c}=v_{g}-L_{a c} \frac{d i_{e v}}{d t}+L_{a c} C_{a c} \frac{d^{2} v_{g}}{d t^{2}}$.

Using a digital control system, the time derivative of the current in the EV $\left(i_{e v}\right)$ represented in (4) can be substituted by its discrete implementation using the forward Euler method according to:

$\frac{d i_{e v}(t)}{d t}=\frac{i_{e v}[k+1]-i_{e v}[k]}{T_{s}}$,

and the second order time derivative of the power grid voltage represented in (4) can be substituted by its discrete implementation according to: $\frac{d^{2} v_{g}(t)}{d t^{2}}=\frac{v_{g}[k+1]-2 v_{g}[k]+v_{g}[k-1]}{T_{s}^{2}}$.

Using (5) and (6), the discrete implementation of (4) results in:

$$
\begin{aligned}
& v_{b c}[k]=v_{g}[\mathrm{k}]-L_{a c} f_{s}\left(i_{e v}[k+1]-i_{e v}[k]\right)+ \\
& \quad+C_{a c} L_{a c} f_{s}^{2}\left(v_{g}[k+1]-2 v_{g}[k]+v_{g}[k-1]\right),
\end{aligned}
$$

where, $f_{s}$ is the sampling frequency, and $k, k-1, k+1$, are respectively, the actual, previous and next time instants. The purpose of this control law is to make the error between the current in the $\operatorname{EV}\left(i_{e v}\right)$ and its reference $\left(i_{e v}{ }^{*}\right)$ equal to zero at the instant $k+1$. Therefore, (7) can be rewritten for:

$$
\begin{aligned}
& v_{b c}[k]=v_{g}[k]-L_{a c} f_{s}\left(i_{e v}{ }^{*}[k]-i_{e v}[k]\right)+ \\
& +C_{a c} L_{a c} f_{s}^{2}\left(v_{g}[k+1]-2 v_{g}[k]+v_{g}[k-1]\right) .
\end{aligned}
$$

In order to compute (8) it is necessary to know the value of the power grid voltage $\left(v_{g}\right)$ in the instant $[k+1]$. This value can be estimated from the present and previous values using a Lagrange extrapolation [40], given by:

$v_{g}[k+1]=3 v_{g}[k]-3 v_{g}[k-1]+v_{g}[k-2]$.

Substituting (9) in (8) is obtained the final current control law that allows to control the current produced by the EV battery charger (i.e., this equation is used to control the ac-dc converter).

Taking into account that the ac-dc front-end converter is a voltage-source converter, when it is controlled in voltage mode, the control of the output voltage is done directly by 


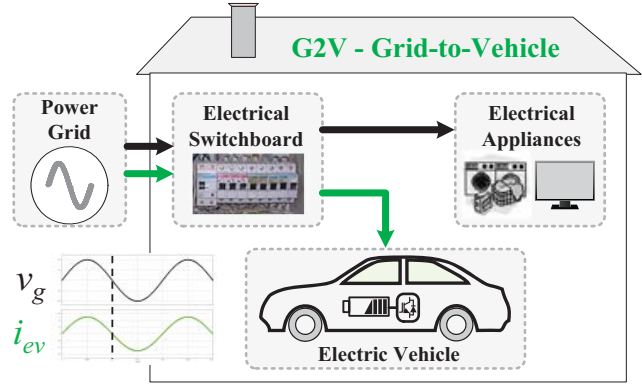

Fig. 3. G2V - Grid-to-vehicle operation mode.

adjusting the duty-cycle value of the PWM modulator. Therefore, the voltage reference is directly compared with a triangular carrier to obtain the gate pulse patterns.

\section{2) Dc-Dc Half-Bridge Bidirectional Converter}

The dc-dc back-end converter is used to charge the batteries in two stages. Taking into account that this EV battery charger is used in an EV with lithium-ion batteries (nominal voltage of $308 \mathrm{~V}$ and nominal capacity of $66 \mathrm{Ah}$ ), the charging process consists in two stages [41]. In a first stage the batteries are charged with constant current (about $80 \%$ of the battery capacity) and in a second stage are charged with a constant voltage (about $20 \%$ of the battery capacity). The current to charge the batteries $\left(i_{b a t}\right)$ is controlled by the dc-dc converter operating as buck-type converter. From Fig. 1(a), analyzing the voltages and currents between the converter and the batteries, it can be established that:

$v_{d c_{-} d c}=v_{b a t}+L_{d c} \frac{d i_{L d c}}{d t}$,

where, $v_{\text {bat }}$ and $i_{\text {bat }}$ are, respectively, the instantaneous values of the voltage in the batteries and the current in the inductor $L_{d c}$. The discrete implementation of (10) results in:

$v_{d c_{-} d c}[k]=v_{\text {bat }}[k]+L_{d c} f_{s}\left(i_{L d c}[k+1]-i_{L d c}[k]\right)$,

where, $i_{L d c}[k+1]$ must be equal to the reference in the instant $[k]$. This equation is used to control the dc-dc converter. The voltage to charge the batteries $\left(v_{b a t}\right)$ is also controlled by the dc-dc converter operating as buck-type converter. In this situation, the output voltage is controlled according to:

$v_{d c_{-} d c}[k]=v_{\text {bat }}{ }^{*}[k]-L_{d c} f_{s}\left(i_{L d c}[k]-i_{L d c}[k-1]\right)$.

The current to discharge the batteries $\left(i_{b a t}\right)$ is controlled by the dc-dc converter operating as boost-type converter. From Fig. 1(a), analyzing the voltages and currents between the converter and the batteries, it can be established:

$v_{d c_{-} d c}=v_{b a t}-L_{d c} \frac{d i_{L d c}}{d t}$.

The discrete implementation of (13) results in:

$v_{d c_{-} d c}[k]=v_{b a t}-L_{d c} f_{s}\left(i_{L d c}[k+1]-i_{L d c}[k]\right)$,

where, $i_{L d c}[k+1]$ must be equal to the reference in the instant $[k]$. Taking into account that the current will follow in opposite sense, in the digital implementation the current $i_{L d c}[k]$ represented in (14) should be $-i_{L d c}[k]$.

The voltage to discharge the batteries $\left(v_{b a t}\right)$ is also controlled by the dc-dc converter operating as boost-type converter. Also in this situation, the control of the output voltage (dc-link voltage) is done directly by adjusting the duty-cycle value of the PWM modulator, i.e., the reference of voltage is directly compared with the carrier in order to obtain the gate pulse patterns.

\section{GRID-TO-Vehicle (G2V) Operation Mode}

Fig. 3 shows the principle of operation of the G2V mode. In this operation mode the power flows from the power grid to the EV batteries. Considering that the power grid voltage $\left(v_{g}\right)$ and the current in the EV $\left(i_{e v}\right)$ are expressed, respectively, by:

$v_{g}=\sqrt{2} V_{G} \sin (\omega t)$,

$i_{e v}=\sqrt{2} I_{E V} \sin (\omega t+\varphi)$,

the mean value of the active power $\left(P_{E V}\right)$ in the ac side of the EV battery charger can be defined by:

$P_{E V}=V_{G} I_{E V} \cos (\varphi)$.

Taking into account that during this operation mode is only transferred active power from the power grid to the batteries, the power grid voltage $\left(v_{g}\right)$ and the current in the $\mathrm{EV}\left(i_{e v}\right)$ are in phase, i.e., $\cos (\varphi)=1$. Therefore, from (17) it can be defined an equivalent conductance $\left(G_{E V}\right)$ according to:

$G_{E V}=\frac{P_{E V}}{V_{G}^{2}}$

where, $V_{G}$ corresponds to the rms value of the power grid voltage. Using the conductance defined in (18), the instantaneous reference for the current in the $\mathrm{EV}$ can be defined by:

$i_{e v}{ }^{*}=G_{E V} p l l_{s} \sqrt{2} V_{g}$.

where, $p l l_{s}$ is in phase with the power grid voltage and has unitary amplitude. The active power $P_{E V}$ can be separated in two terms corresponding, respectively, to the power to charge the batteries and the power to regulate the dc-link voltage $\left(v_{d c}\right)$. Therefore, substituting (18) in (19) is obtained:

$i_{e v}{ }^{*}=\frac{P_{D C}+v_{b a t} i_{b a t}}{V_{g}{ }^{2}} p l l_{s} \sqrt{2} V_{g}$,

where, $P_{D C}$ is obtained from a PI controller, which is used to maintain the dc-link voltage $\left(v_{d c}\right)$ equal to the reference. Substituting (20) in (8) is obtained the final grid current control strategy for the ac-dc front-end converter during the G2V operation mode.

During this operation mode the dc-dc converter operates as buck-type converter, allowing the control of the voltage and current to charge the batteries. The current reference to charge the batteries is provided to the EV battery charger by the battery management system (BMS) through CAN-Bus communication (cf. Fig. 1(b)). This current reference is used in (11). The voltage reference is also provided by the BMS and is used to adjust the duty-cycle of the PWM modulator. In accordance with the EV batteries manufacturer's recommendations, the dc-dc converter is controlled in both constant current and constant voltage stages.

Fig. 4 shows the experimental results of the battery charger in the $\mathrm{G} 2 \mathrm{~V}$ operation mode. It is possible to see the power grid voltage $\left(v_{g}\right)$ and the current in the $\operatorname{EV}\left(i_{e v}\right)$. The current in the 


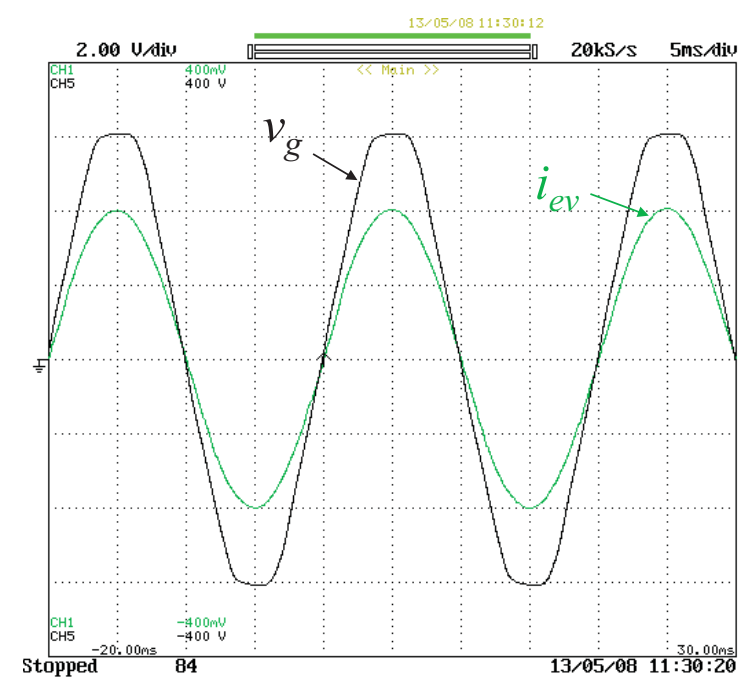

Fig. 4. Experimental results of the EV battery charger in G2V operation mode: Power grid voltage $\left(v_{g}: 100 \mathrm{~V} /\right.$ div $)$ and current in the $\mathrm{EV}\left(i_{e v}: 5 \mathrm{~A} /\right.$ div $)$.

EV $\left(i_{e v}\right)$ is sinusoidal and in phase with the power grid voltage $\left(v_{g}\right)$. The measured power factor was 0.99 and the current total harmonic distortion (THDi\%) was $1 \%$. It is important to refer that these values were obtained due to the passive components $L_{a c}$ and $C_{a c}$ that help filtering the high frequencies (cf. section II.A). The power grid voltage $\left(v_{g}\right)$ has a THDv\% of $3 \%$ due to the nonlinear electrical appliances in the electrical installation and the line impedance. It is also important to refer that, taking into account that the current in the $\mathrm{EV}$ is sinusoidal, the voltage in the power line impedance due to this current is also sinusoidal, not contributing to the harmonic distortion of the power grid voltage.

\section{Vehicle-TO-GRid (V2G) Operation Mode}

Fig. 5 shows the principle of operation of the $\mathrm{V} 2 \mathrm{G}$ mode. In this operation mode the power flows from the EV batteries to the power grid. The G2V mode is the main operation mode of the EV bidirectional battery charger, however, during some periods of time (in accordance with the requirements of the power grid and the convenience of the EV driver), the battery charger can be used in V2G mode to deliver part of the energy stored in the batteries back to the power grid. During this operation mode the ac-dc front-end converter is used to control the current in order to be in phase opposition with the power grid voltage. In a smart grid scenario, this operation mode is controlled by the power grid manager and in accordance with the EV driver. Therefore, when it is required deliver energy from the EV batteries to the power grid, the EV receives set points of energy (i.e., a reference value of an active power $\left(P_{A C}{ }^{*}\right)$ and an interval of time) and control the batteries current $\left(i_{b a t}\right)$ to obtain the reference of current for the EV $\left(i_{e v}{ }^{*}\right)$. Neglecting the power losses, the reference of current in the batteries $\left(i_{b a t}{ }^{*}\right)$ is obtained according to:

$i_{\text {bat }}{ }^{*}=\frac{P_{A C}{ }^{*}}{v_{\text {bat }}}$.

Using (21) the reference of current for the $\mathrm{EV}\left(i_{e v}{ }^{*}\right)$ is obtained according to:

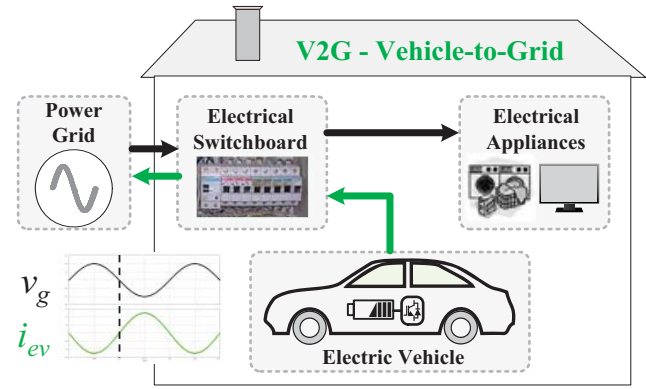

Fig. 5. V2G - Vehicle-to-grid operation mode.

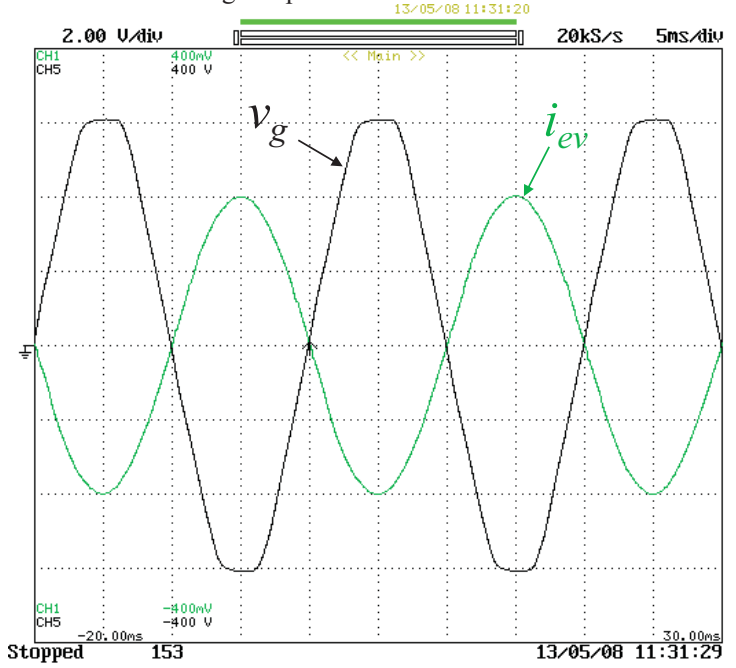

Fig. 6. Experimental results of the EV battery charger in $\mathrm{V} 2 \mathrm{G}$ operation mode: Power grid voltage ( $v_{g}: 100 \mathrm{~V} /$ div $)$ and current in the EV $\left(i_{e v}: 5 \mathrm{~A} /\right.$ div $)$.

$i_{e v}{ }^{*}=\frac{P_{D C}+i_{b a t}{ }^{*} v_{b a t}}{V_{g}{ }^{2}} p l l_{s} \sqrt{2} V_{g}$.

During this operation mode the dc-dc converter operates as boost-type converter, i.e., it is used to control the battery current $\left(i_{b a t}\right)$. The reference of current to discharge the batteries (cf. (21)) is used in (14). Fig. 6 shows the experimental results of the EV battery charger in the V2G operation mode. This figure shows the power grid voltage $\left(v_{g}\right)$ and the current in the EV $\left(i_{e v}\right)$ during the V2G operation mode. As in the G2V operation mode, the current is sinusoidal, but in phase opposition with the power grid voltage, meaning that the power flows from the EV batteries to the power grid. Also in this operation mode the measured power factor was 0.99 and the THDi\% was $1 \%$.

\section{Home-To-Vehicle (H2V) Operation Mode}

Fig. 7 shows the principle of operation of the $\mathrm{H} 2 \mathrm{~V}$ mode. In this operation mode the power flows from the power grid to the EV batteries, or vice-versa, in accordance with the energy provided to the other electrical appliances in the home. The $\mathrm{H} 2 \mathrm{~V}$ operation mode is an improvement of the G2V and V2G operation modes. It consists in adjusting the current or voltage during the batteries charging (relation with the G2V operation mode), or in adjusting the current during the batteries discharging (relation with the $\mathrm{V} 2 \mathrm{G}$ operation mode). It is important to note that the operation in these two cases is totally independent. 


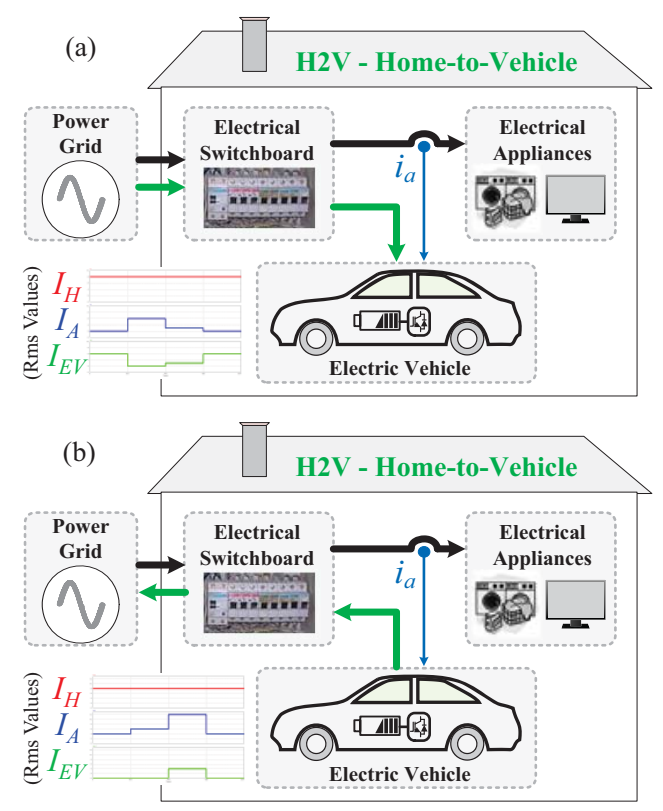

Fig. 7. H2V - Home-to-vehicle operation mode: (a) Combined with G2V; (b) Combined with V2G.

\section{A. H2V Combined with Grid-to-Vehicle}

During this operation mode the power flows from the power grid to the EV batteries in accordance with the power required by the other electrical appliances in the home. This functionality aims to prevent overcurrent trips of the main circuit breaker installed in the home. Therefore, the rms current in the $\mathrm{EV}\left(I_{E V}\right)$ is the difference between the total current admissible in the home $\left(I_{H_{-} \max }\right)$ and the current in the electrical appliances $\left(I_{A}\right)$, which is expressed by:

$I_{E V}=I_{H_{-} \max }-I_{A}$.

Therefore, to perform this operation mode it is required measuring the current in the electrical appliances $\left(i_{a}\right)$, and sending the measured value to the EV battery charger. As presented in [27], the current of the electrical appliances is measured in the home electrical switchboard and sent to the $\mathrm{EV}$ through wired communication (when the EV is plugged at home). This current is acquired by the EV battery charger through the connector identified in Fig. 1(b) as "Measured Signals". The EV battery charger uses the measured value of current to adjust its own instantaneous current in accordance with those values. In order to implement this smart charging strategy, it is established that the maximum power available in the home is the power defined by the signed contract with the electricity service provider. To guarantee that the contracted power is not exceeded, the service provider installs a circuit breaker rated to the nominal current. In this situation, the maximum current allowed (the current in the electrical appliances plus the current in the EV) is established by the main circuit breaker installed in the home electrical switchboard. It is important to refer that in a typical situation, the EV is plugged in a home socket to perform the battery charging process without any concern about the contracted power for the home.

In order to obtain reliable data about an EV battery charging process it was monitored the EV Renault Fluence charging process. The obtained results are presented in detail in [42]. This monitoring was performed at under secure and controlled conditions and with an appropriated electrical installation. To obtain the results was used a FLUKE 435 Power Quality Analyzer, programmed to register every 1 minute the rms value of the power grid voltage and the current in the EV. The EV battery charging process was monitored several times in different conditions, for instance, performing the battery charging process after a full discharge and with different ambient temperatures. In [27] are presented some preliminary experimental results in a single-phase installation of $230 \mathrm{~V}$ $50 \mathrm{~Hz}$, where is illustrated that was not possible perform the EV charging process due to the current in the electrical appliances, i.e., without a smart charging strategy. Also in [27] is demonstrated, through experimental results that using a smart EV battery charging process, the total current in the home is maintained below the limit, and the circuit breaker trips are avoided. It is important to refer that using this strategy it can be required more time than the expected (according to the time specified by the EV manufacturer) to perform the full EV battery charging process. However, the circuit breaker never trips during the EV battery charging process. It is also important to note that the overcurrent situation (circuit breaker trips) can occur even with dedicated $\mathrm{EV}$ home installation, once it is not possible predict the electrical appliances connected at the home electrical installation. Although these results portray a specific case, it is quite representative of the EV battery charging at home.

During this operation mode the ac-dc front-end converter operates as in the $\mathrm{G} 2 \mathrm{~V}$ operation mode presented in section III. On the other hand, the dc-dc back-end converter operates as buck-type converter, however, the current in the batteries $\left(i_{b a t}\right)$ is controlled in function of the current in the home electrical appliances $\left(i_{a}\right)$, and the total current allowed to the home. After obtaining the current in home electrical appliances $\left(i_{a}\right)$, it is calculated its rms value $\left(I_{A}\right)$ according with:

$I_{A}[k]=\sqrt{\frac{1}{N} \sum_{k=1}^{k=N} i_{a}{ }^{2}[k] .}$

where, $N$ is the number of samples used in each cycle of the power grid voltage (in this case, using a sampling frequency of $40 \mathrm{kHz}, N=800$ ). This equation allows calculate the rms value during one cycle $(50 \mathrm{~Hz})$ of the power grid voltage. Therefore, neglecting the converter losses, which does not introduce significant error to the circuit analysis, the current reference in the batteries $\left(i_{b a t} *\right)$ is obtained according to:

$i_{\text {bat }}{ }^{*}=\frac{V_{G}}{v_{\text {bat }}}\left(I_{H_{-} \max }-I_{A}\right)$,

where, $I_{H}$ max is the maximum rms value for the total current in the home. This reference current is used in (11) in order to control the dc-dc half-bridge bidirectional converter during the charging stage with constant current. During the charging stage with constant voltage the reference $\left(v_{b a t}{ }^{*}\right)$ is obtained according to: 


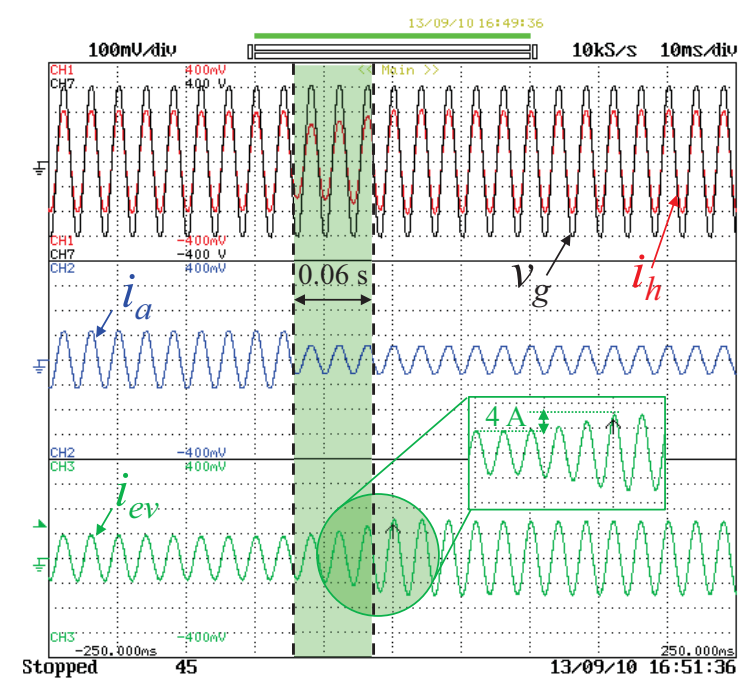

Fig. 8. Experimental results of the EV battery charger in $\mathrm{H} 2 \mathrm{~V}$ operation mode (combined with G2V): Instantaneous values of the power grid voltage $\left(v_{g}: 100 \mathrm{~V} / \mathrm{div}\right)$, total current in the home $\left(i_{h}: 5 \mathrm{~A} / \mathrm{div}\right)$, current only in the home electrical appliances $\left(i_{a}: 5 \mathrm{~A} / \mathrm{div}\right)$, and current in the $\mathrm{EV}\left(i_{e v}: 5 \mathrm{~A} / \mathrm{div}\right)$.

$v_{\text {bat }}{ }^{*}=\frac{V_{G}}{i_{\text {bat }}{ }^{*}}\left(I_{H_{-} \max }-I_{A}\right)$.

From (20) and (25), the reference of current for the ac-dc front-end converter is obtained according to:

$i_{e v}{ }^{*}=\frac{P_{D C}+\left(I_{H_{-} \max }-I_{A}\right) V_{g}}{V_{g}{ }^{2}} p l l_{s} \sqrt{2} V_{g}$.

This reference of current is used in (8) in order to control the ac-dc front-end converter. Fig. 8 shows experimental results of the EV battery charger in the $\mathrm{H} 2 \mathrm{~V}$ operation mode (combined with the G2V). This figure shows the instantaneous values of the power grid voltage $\left(v_{g}\right)$, the total current in the home $\left(i_{h}\right)$, the current in the home electrical appliances $\left(i_{a}\right)$, and the current in the EV $\left(i_{e v}\right)$. As it can be seen, the current in the $\operatorname{EV}\left(i_{e v}\right)$ is adjusted in function of the variation in the current in the home electrical appliances $\left(i_{a}\right)$ in three cycles of the power grid voltage, i.e., in $0.06 \mathrm{~s}$. This interval of time is used to calculate the rms value of the current in the home electrical appliances $\left(i_{a}\right)$, and the remaining time of the referred interval is used to adjust slowly the current in the EV $\left(i_{e v}\right)$ in order to avoid sudden variations in the total current in the home $\left(i_{h}\right)$.

Fig. 9 shows experimental results of the response of the current in the EV in function of changes in the current in the home electrical appliances, during a period of 50 seconds. In this figure is presented, respectively, the rms values of the total current in the home $\left(I_{H}\right)$, the current in the home electrical appliances $\left(I_{A}\right)$, and the current in the EV $\left(I_{E V}\right)$. As can be seen, the current in the EV $\left(I_{E V}\right)$ is adjusted with a smooth response, after a delay needed to calculate the rms value of the current in the electrical appliances $\left(I_{A}\right)$. In this situation the total home current is maintained almost constant and equal to $15 \mathrm{~A}$, while the load current has a maximum variation of $5 \mathrm{~A}$, causing a variation with the same amplitude in the $\mathrm{EV}\left(I_{E V}\right)$ current.

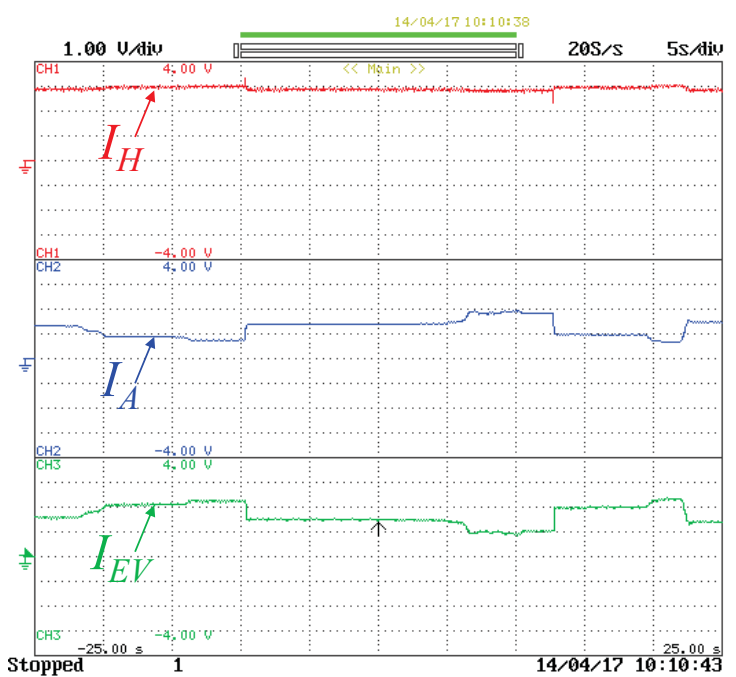

Fig. 9. Experimental results of the EV battery charger in $\mathrm{H} 2 \mathrm{~V}$ operation mode (combined with G2V): Rms values of the total current in the home $\left(I_{H}: 5 \mathrm{~A} / \mathrm{div}\right)$, current only in the home electrical appliances $\left(I_{A}: 5 \mathrm{~A} / \mathrm{div}\right)$, and current in the $\mathrm{EV}\left(I_{E V}: 5 \mathrm{~A} / \mathrm{div}\right)$

\section{B. H2V combined with Vehicle-to-Grid}

During this operation mode the power flows from the EV batteries to the power grid also in accordance with the power that flows to the other electrical appliances. This functionality also aims to prevent overcurrent trips of the main circuit breaker installed in the home. However, it is used when the current in the home electrical appliances $\left(I_{A}\right)$ exceeds the maximum total current in the home $\left(I_{H_{-} \max }\right)$. Therefore, the current in the $\mathrm{EV}\left(I_{E V}\right)$ is the difference between the current in the electrical appliances $\left(I_{A}\right)$ and the total current in the home $\left(I_{H_{-} \max }\right)$, which is expressed by:

$I_{E V}=I_{A}-I_{H_{-} \max }$.

In this situation the reference current in the batteries $\left(i_{b a t} *\right)$ is obtained in accordance with:

$i_{\text {bat }}{ }^{*}=\frac{V_{G}}{v_{\text {bat }}}\left(I_{A}-I_{H_{-} \max }\right)$.

Also in this situation, this reference current is used in (14) in order to control the dc-dc converter. From (20) and (29), the reference of current for the ac-dc front-end converter is obtained according to:

$i_{e v}{ }^{*}=\frac{P_{D C}-\left(I_{A}-I_{H_{-} \max }\right) V_{g}}{V_{g}{ }^{2}} p l l_{s} \sqrt{2} V_{g}$.

This reference of current is used in (8) in order to control the ac-dc front-end converter. Fig. 10 shows experimental results of the response of the current in the EV in function of changes in the current in the home electrical appliances, during a period of 5 seconds. In this figure is presented, respectively, the rms values of the total current in the home $\left(I_{H}\right)$, the current in the electrical appliances $\left(I_{A}\right)$, and the current in the EV $\left(I_{E V}\right)$. As can be seen, the total current in the home is maintained almost constant and equal to $15 \mathrm{~A}$, while the load current has a maximum variation of $7 \mathrm{~A}$, which corresponds to the maximum variation in the current in the EV $\left(I_{E V}\right)$. 


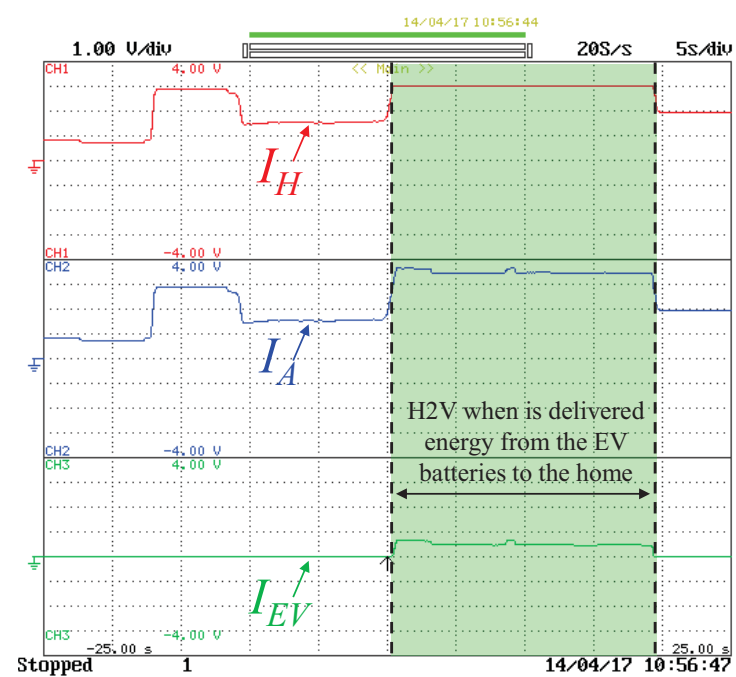

Fig. 10. Experimental results of the EV battery charger in $\mathrm{H} 2 \mathrm{~V}$ operation mode (combined with V2G): Rms values of the total current in the home $\left(I_{H}: 5 \mathrm{~A} / \mathrm{div}\right)$, current only in the home electrical appliances $\left(I_{A}: 5 \mathrm{~A} / \mathrm{div}\right)$, and current in the $\mathrm{EV}\left(I_{E V}: 5 \mathrm{~A} /\right.$ div $)$.

\section{VEHICLE-FOR-GRID (V4G) OPERATION MODE}

Fig. 11 shows the principle of operation of the V4G mode. In this operation mode the EV can be used only to produce reactive power or to operate as active power filter (i.e., compensating harmonics in the total current in the home). When the EV battery charger is connected to the power grid, but it is not operating in the $\mathrm{G} 2 \mathrm{~V}$ or $\mathrm{V} 2 \mathrm{G}$ operation modes, it can operate in the V4G only to produce inductive or capacitive reactive power and to compensate current harmonics. In this case, the total rated power of the EV battery charger can be used to that matter (without using any energy from the batteries). On the other hand, the V4G operation mode can be performed at the same time that the EV battery charger is working in $\mathrm{G} 2 \mathrm{~V}$ (charging the batteries) or when it is working in $\mathrm{V} 2 \mathrm{G}$ (returning part of the energy stored in the batteries back to the power grid). However, in these cases, only part of the rated power of the EV battery charger, which is not being used for the $\mathrm{G} 2 \mathrm{~V}$ or $\mathrm{V} 2 \mathrm{G}$ modes, can be used to produce reactive power or to compensate current harmonics.

\section{A. Producing Reactive Power}

During this operation mode the EV is used to produce reactive power according to set points received from the power grid manager. For such purpose, the EV receives a value of reactive power $\left(Q^{*}\right)$ and a value of a time interval. It is important to refer that the maximum reactive power that the EV can produce cannot exceed the nominal power of the EV. For instance, if the EV is operating in the G2V mode with a power of $2 \mathrm{~kW}$, then the maximum reactive power that the EV can compensate is $3 \mathrm{kVAr}$. Therefore, the reference current for the ac-dc front-end converter is obtained according to:

$i_{e v}{ }^{*}=\frac{P_{D C}+\left(i_{b a t}{ }^{*} v_{b a t}\right)}{V_{g}{ }^{2}} p l l_{s} \sqrt{2} V_{g}+\frac{Q^{*}}{V_{g}{ }^{2}} p l l_{c}$

where, $Q^{*}$ denotes the reactive power reference and $p l l_{c}$ is the signal obtained from the PLL that is in quadrature with $p l l_{s}$.

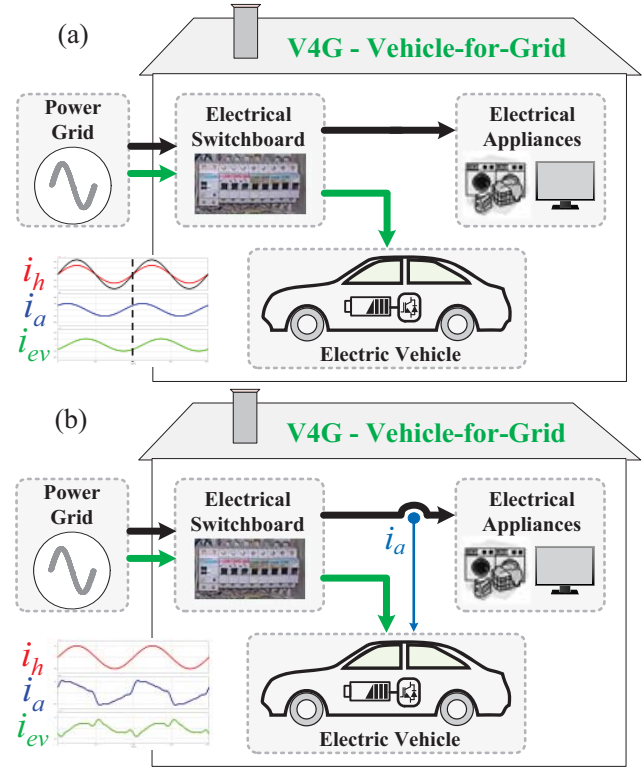

Fig. 11. V4G - Vehicle-for-grid operation mode: (a) Producing reactive power; (b) Compensating current harmonics.

On the other hand, the dc-dc half-bridge bidirectional converter operates as described for the $\mathrm{G} 2 \mathrm{~V}$ operation mode (cf. section III) or for the V2G operation mode (cf. section IV). If this operation mode is combined with the V2G mode, then the current $i_{b a t}[k]$ should be $-i_{b a t}[k]$. Fig. 12 shows experimental results of the EV battery charger in the $\mathrm{V} 4 \mathrm{G}$ operation mode. This figure shows the power grid voltage $\left(v_{g}\right)$ and the current in the $\mathrm{EV}\left(i_{e v}\right)$ for an active power of $1.05 \mathrm{~kW}$ and a reactive power of $0.764 \mathrm{kVAr}$ (capacitive). On the other hand, Fig. 13 shows the same variables, but for a reactive power of $0.764 \mathrm{kVAr}$ (inductive).

\section{B. Compensating Current Harmonics}

During this operation mode the EV is used to compensate the current harmonics of the total current in the home $\left(i_{h}\right)$. When the EV is used to compensate current harmonics, in order to determine the reference of current for the $\mathrm{EV}$, it is necessary measure the instantaneous value of the current in the home electrical appliances $\left(i_{a}\right)$. As referred in section $\mathrm{V}$, this current is acquired by the EV battery charger through the connector identified in Fig. 1(b) as "Measured Signals". With this current and the power grid voltage $\left(v_{g}\right)$ is calculated the instantaneous value of the power in the home electrical appliances $\left(p_{a}\right)$ according to:

$p_{a}[k]=v_{g}[k] i_{a}[k]$,

and the average value of this instantaneous power according with:

$\operatorname{sum}[k]=\operatorname{sum}[k-1]-p_{a}[k-N]+p_{a}[k]$,

$\overline{P_{A}}[k]=\frac{\operatorname{sum}[k]}{N}$,

where, $N$ denotes the number of samples used in each cycle of the power grid voltage. With the average value of the power and the instantaneous current in the electrical appliances $\left(i_{a}\right)$ is calculated the instantaneous value of the reference current in the $\mathrm{EV}\left(i_{e v}{ }^{*}\right)$ according to: 


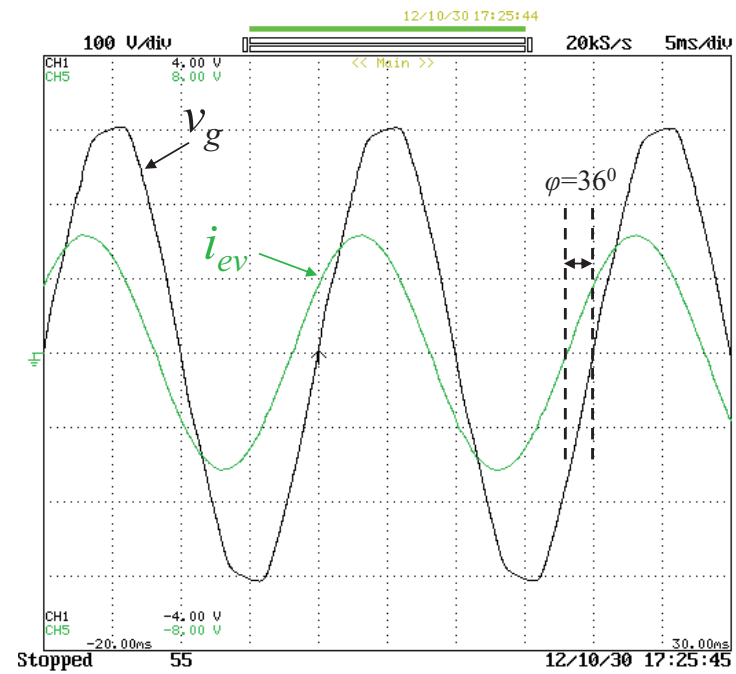

Fig. 12. Experimental results of the EV battery charger in V4G operation mode producing reactive power: Power grid voltage $\left(v_{g}: 100 \mathrm{~V} / \mathrm{div}\right)$ and current in the $\mathrm{EV}\left(i_{e v}: 5 \mathrm{~A} / \mathrm{div}\right)$ for an active power of $1.05 \mathrm{~kW}$ and a reactive power of $0.764 \mathrm{kVAr}$ (capacitive).

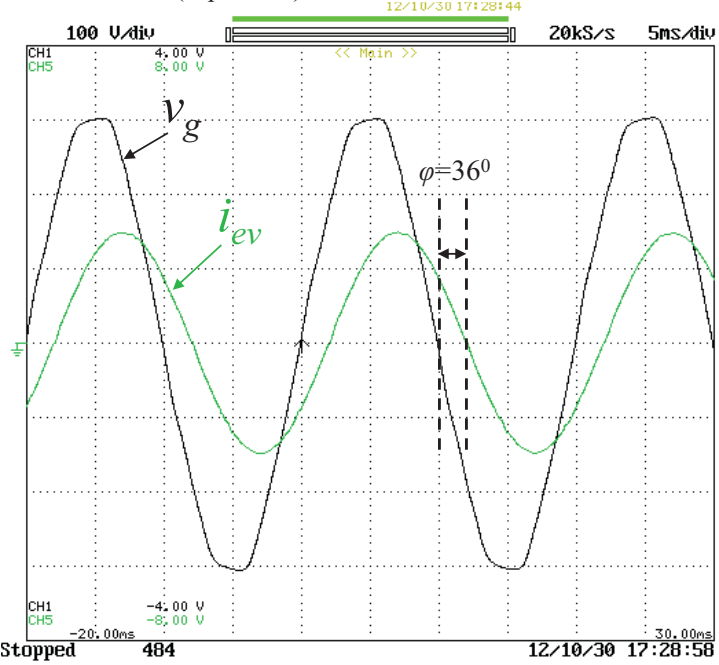

Fig. 13. Experimental results of the EV battery charger in $\mathrm{V} 4 \mathrm{G}$ operation mode producing reactive power: Power grid voltage $\left(v_{g}: 100 \mathrm{~V} /\right.$ div $)$ and current in the $\mathrm{EV}\left(i_{e v}: 5 \mathrm{~A} / \mathrm{div}\right)$ for an active power of $1.05 \mathrm{~kW}$ and a reactive power of $0.764 \mathrm{kVAr}$ (inductive)

$i_{e v}{ }^{*}=\frac{\left(P_{D C}+i_{b a t}{ }^{*} v_{b a t}\right)}{V_{G}{ }^{2}} p l l_{s} \sqrt{2} V_{g}+\frac{\overline{P_{a}}}{{V_{G}}^{2}} p l l_{s} \sqrt{2} V_{g}-i_{a}$

If this operation mode is combined with the $\mathrm{V} 2 \mathrm{G}$, then the current $i_{b a t}[k]$ should be $-i_{b a t}[k]$. Fig. 14 shows experimental results of the instantaneous values of the power grid voltage $\left(v_{g}\right)$, the total current in the home $\left(i_{h}\right)$, the current in the home electrical appliances $\left(i_{a}\right)$, and the current in the EV $\left(i_{e v}\right)$. This results was obtained with the $\mathrm{EV}$ only compensating the current harmonics, i.e., without charging the batteries $\left(P_{B A T}=0\right)$. As it can be seen, due to the EV operation in this mode, i.e., with the current produced by the EV in function of the current in the home electrical appliances $\left(i_{a}\right)$, the total home current $\left(i_{h}\right)$ is sinusoidal and in phase with the power grid voltage. The measured THDi\% in the total home current $\left(i_{h}\right)$ was $2 \%$ and the total power factor was 0.99 . Fig. 15 shows the same variables that were presented for Fig. 14. However, these results were obtained with the EV compensating the

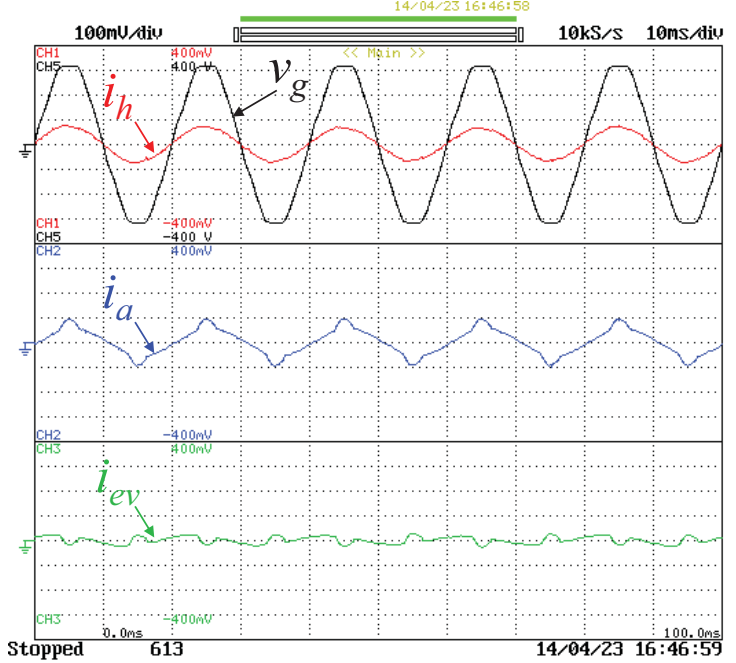

Fig. 14. Experimental results of the EV battery charger in V4G operation mode compensating current harmonics and with $P_{B A T}=0 \mathrm{~kW}$ : Power grid voltage $\left(v_{g}: 100 \mathrm{~V} / \mathrm{div}\right)$, total current in the home $\left(i_{h}: 5 \mathrm{~A} / \mathrm{div}\right)$, current only in the home electrical appliances $\left(i_{a}: 5 \mathrm{~A} / \mathrm{div}\right)$, and current in the $\mathrm{EV}$ $\left(i_{e v}: 5 \mathrm{~A} / \mathrm{div}\right)$.

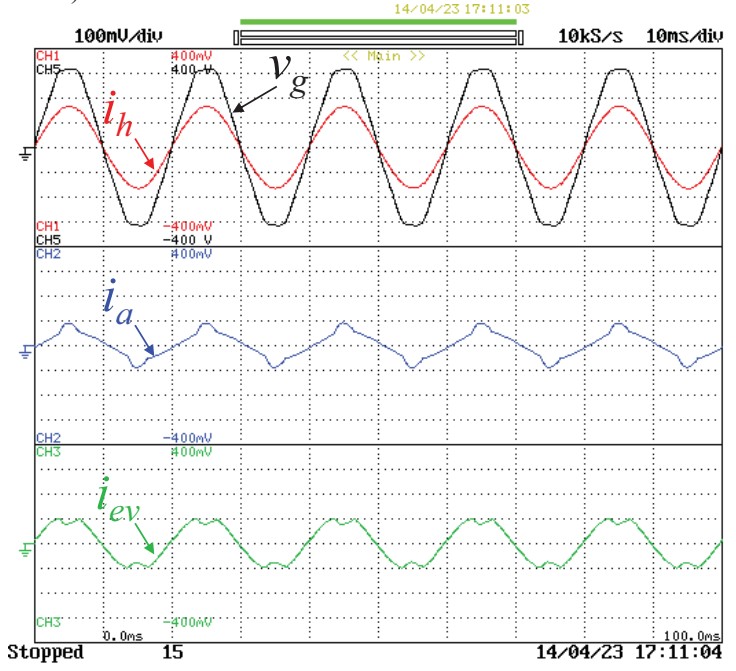

Fig. 15. Experimental results of the EV battery charger in V4G operation mode compensating current harmonics and with $P_{B A T}=1 \mathrm{~kW}$ : Power grid voltage $\left(v_{g}: 100 \mathrm{~V} / \mathrm{div}\right)$, total current in the home $\left(i_{h}: 5 \mathrm{~A} / \mathrm{div}\right)$, current only in the home electrical appliances $\left(i_{a}: 5 \mathrm{~A} / \mathrm{div}\right)$, and current in the EV $\left(i_{e v}: 5 \mathrm{~A} / \mathrm{div}\right)$.

current harmonics and also charging the batteries $\left(P_{B A T}=1 \mathrm{~kW}\right)$. Also, in this operation mode, due to the EV operation, the total home current $\left(i_{h}\right)$ is sinusoidal and in phase with the power grid voltage. The measured THDi\% in the total home current $\left(i_{h}\right)$ was $2 \%$ and the total power factor was 0.99 .

\section{VehiCLE-TO-HOME (V2H) OpERATION MODE}

Fig. 16 shows the principle of operation of the V2H mode. The V2H operation mode is totally independent of the G2V and $\mathrm{V} 2 \mathrm{G}$ operation modes. In the $\mathrm{V} 2 \mathrm{H}$ mode the EV battery charger is controlled to operate as a voltage source, where the batteries are the power source. This operation mode is divided in two distinct cases, i.e., when the EV battery charger is used to provided energy to electrical appliances in isolated systems or when the EV battery charger is used to operate as an off-line UPS. In both cases the batteries are discharged 
without any control of the discharging current because the dc-dc converter is only controlled to maintain the dc-link voltage regulated.

\section{A. Isolated Systems}

During this operation mode the EV operates as voltage-source for isolated systems. For such purpose, the ac-dc front-end converter is controlled in order to synthetize a sine wave voltage with the desired amplitude and frequency to feed the home electrical appliances. During this operation mode the dc-dc converter operates as a boost-type converter in order to maintain the dc-link voltage with an adequate amplitude for the proper operation of the ac-dc front-end converter. During this operation mode the dc-link voltage $\left(v_{d c}\right)$ is controlled according to:

$v_{d c_{-} d c}[k]=v_{d c}{ }^{*}[k]-v_{\text {bat }}[k]$,

and the voltage $\left(v_{e v}\right)$ is controlled according to:

$v_{b c}[k]=v_{e v}{ }^{*}[k]-L_{a c}\left(i_{\text {Lac }}[k]-i_{\text {Lac }}[k-1]\right)$.

Taking into account that the EV operates disconnected from the power grid, the reference voltage $\left(v_{e v}{ }^{*}\right)$ is obtained from a sine table stored in the internal memory of the digital controller. Fig. 17 shows experimental results of the EV battery charger in the $\mathrm{H} 2 \mathrm{~V}$ operation mode (in isolate systems). In this operation mode is used energy from the EV battery to supply the home electrical appliances. In this experimental result was used a linear load, i.e., a resistive load of $34 \Omega$. This figure shows the voltage produced by the EV $\left(v_{e v}\right)$ and the current in the home electrical appliances $\left(i_{a}\right)$.

\section{B. Uninterruptible Power Supply}

During this operation mode the EV operates as an off-line UPS. Therefore, it is necessary implement an algorithm to detect power outages. In the scope of this paper was used an algorithm based on the estimation of the rms value using a Kalman filter. For such purpose, it was defined that a power outage occurs when the rms value of the power grid voltage is below $90 \%$ of its nominal value (standard EN 50160). During this operation mode, when is detected a power outage the switch $s w$, represented in Fig. 1, is open and the home is disconnected from the power grid.

The algorithm for estimating the rms values using the Kalman filter is more complex than the traditional method using the rms calculation, however, in most of the situations it is faster to detect variations in the rms value. The Kalman filter is based in two distinct set of equations: Prediction and Correction [43]. The estimation of the rms value of the power grid voltage is given by:

$\widehat{V}_{G}[k]=\sqrt{\frac{\hat{s}[k]^{2}+\hat{q}[k]^{2}}{2}}$,

where, $\hat{s}[k]$ and $\hat{q}[k]$ denotes the estimation of the in-phase and quadrature signals of the state model. Using this algorithm, the rms value of the power grid voltage $\left(v_{g}\right)$ is continuously estimated and compared with a threshold of $90 \%$ of the nominal value. When the estimated rms value is below the reference of $90 \%$, it is assumed that a power outage

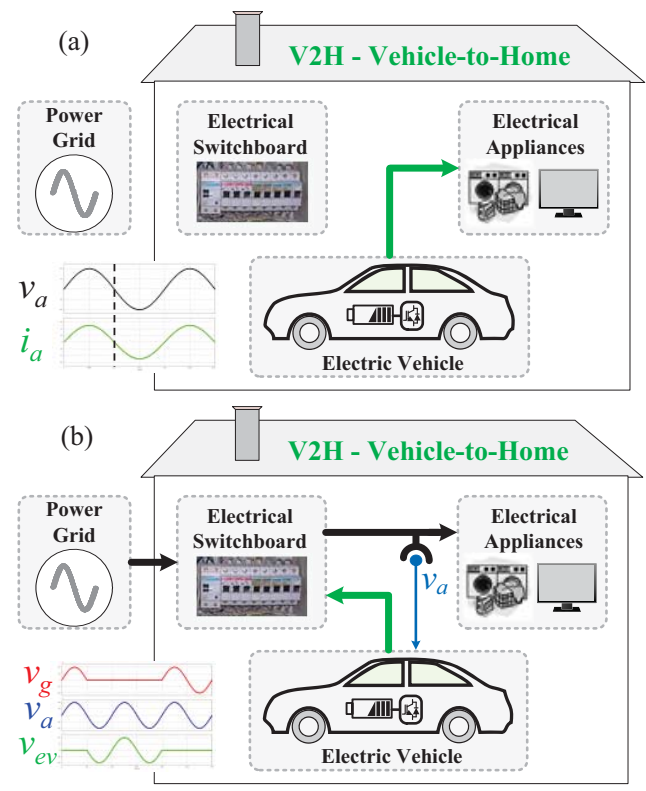

Fig. 16. V2H - Vehicle-to-home operation mode: (a) Operation in isolated systems; (b) Operation as an off-line UPS.

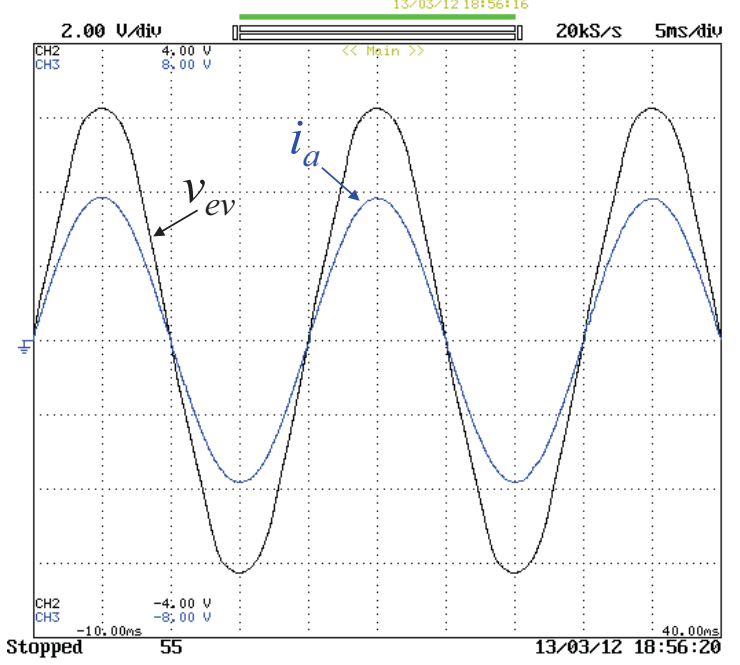

Fig. 17. Experimental results of the EV battery charger in $\mathrm{H} 2 \mathrm{~V}$ operation mode (in isolated electrical systems): Voltage produced by the EV $\left(v_{e v}: 100 \mathrm{~V} / \mathrm{div}\right)$ and current in the home electrical appliances $\left(i_{a}: 5 \mathrm{~A} / \mathrm{div}\right)$.

occurs, and thus the EV must operate in $\mathrm{V} 2 \mathrm{H}$ operation mode as an off-line UPS. Fig. 18 shows experimental results of the EV battery charger in the $\mathrm{H} 2 \mathrm{~V}$ operation mode as off-line UPS. This figure shows the instantaneous values of the voltage $\left(v_{e v}\right)$ and the current $\left(i_{a}\right)$ in the home electrical appliances when is detected a power outage. As it can be seen, before the transition, the voltage applied to the home electrical appliances is the power grid voltage, and after the transition the voltage applied is the voltage produced by the EV. In this situation were required $0.4 \mathrm{~ms}$ for a complete transition, i.e., to detect the power outage and for the EV to start operation as a voltage source. Fig. 19 shows the voltage and current in the home electrical appliances $\left(v_{a}\right.$ and $i_{a}$ ) and the current in the EV $\left(i_{e v}\right)$. In this situation it was used a nonlinear electrical appliance (which is a more realistic condition) in order to validate the $\mathrm{V} 2 \mathrm{H}$ operation mode as an off-line UPS. When a 


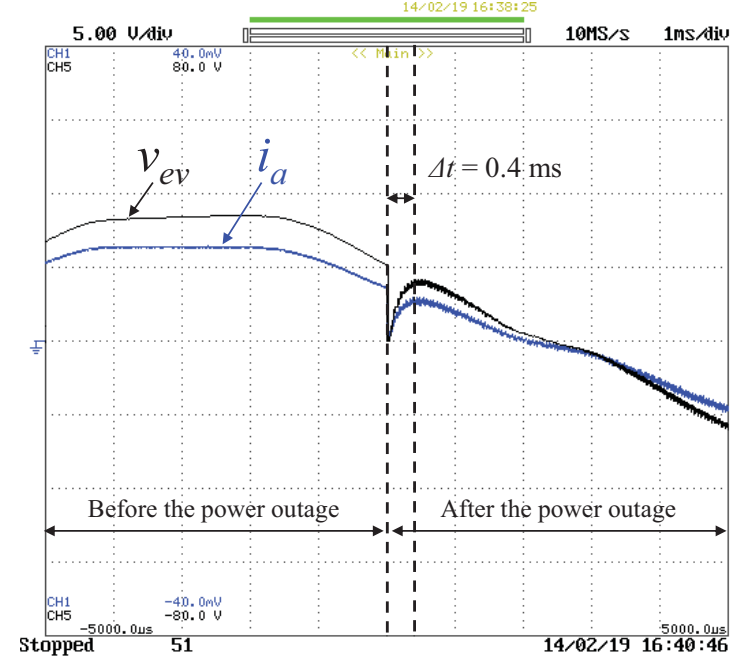

Fig. 18. Experimental results of the EV battery charger in $\mathrm{H} 2 \mathrm{~V}$ operation mode as off-line UPS: Voltage in the home electrical appliances $\left(v_{a}: 190 \mathrm{~V} / \mathrm{div}\right)$ and current in the home electrical appliances $\left(i_{a}: 5 \mathrm{~A} / \mathrm{div}\right)$.

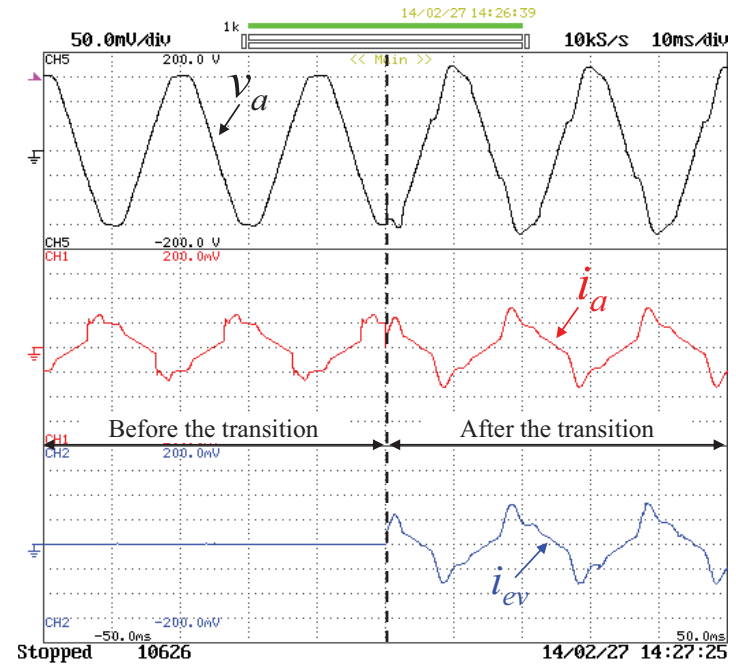

Fig. 19. Experimental results of the EV battery charger in $\mathrm{H} 2 \mathrm{~V}$ operation mode as an off line UPS: Voltage in the home electrical appliances $\left(v_{a}: 100 \mathrm{~V} / \mathrm{div}\right)$; Current in the home electrical appliances $\left(i_{a}: 5 \mathrm{~A} / \mathrm{div}\right)$; Current in the EV ( $\left.i_{e v}: 5 \mathrm{~A} / \mathrm{div}\right)$.

power outage is detected, the EV operates as a voltage-source producing the voltage applied to the home electrical appliances $\left(v_{a}\right)$, and consequently, the current in the electrical appliances $\left(i_{a}\right)$ is the same current of the $\operatorname{EV}\left(i_{e v}\right)$. As aforementioned, when is detected a power outage the switch $s w$ is open and the home is disconnected from the power grid. When the power grid voltage is restored the switch $s w$ is closed, however, only after a delay necessary to the complete synchronization of the PLL with the power grid voltage. Fig. 20 shows experimental results of the EV battery charger in the $\mathrm{H} 2 \mathrm{~V}$ operation mode as off-line UPS. This figure shows the power grid voltage $(\mathrm{vg})$, and the digital values (values in the DSP and obtained with a digital-to-analogue converter) of the power grid voltage and the PLL signal $\left(v_{p l l s}\right)$. As it can be seen, before the power grid voltage restoration, the $v_{\text {plls }}$ is sinusoidal and with the same amplitude of the power grid voltage $\left(v_{g}\right)$. After the restoration, the $v_{\text {plls }}$ is forced to synchronize with the power grid voltage. For such purpose

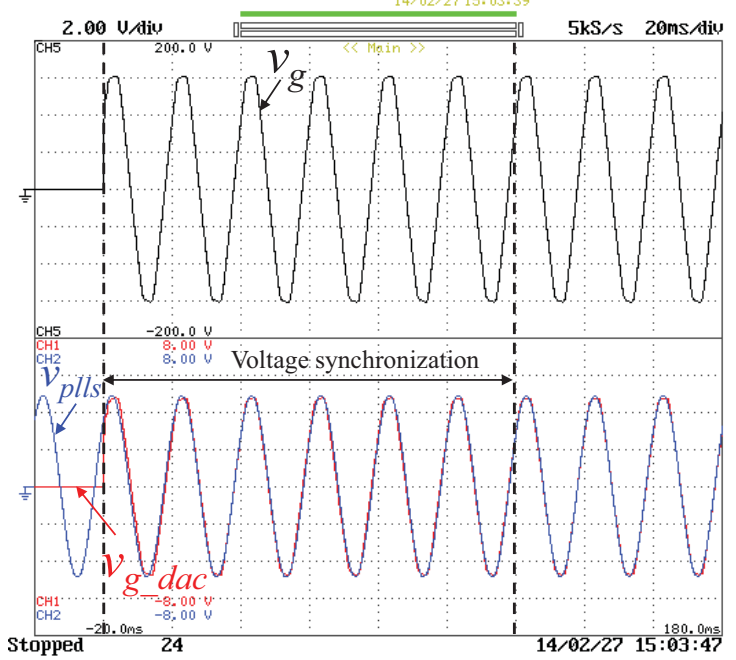

Fig. 20. Experimental results of the EV battery charger in $\mathrm{H} 2 \mathrm{~V}$ operation mode as off-line UPS: Power grid voltage $\left(v_{g}: 100 \mathrm{~V} / \mathrm{div}\right)$ and digital values of the $v_{\text {plls }}$ and power grid voltage $\left(v_{g_{-} d a c}\right)$ during the synchronization of the $v_{\text {plls }}$ with the restored power grid voltage $\left(v_{g}\right)$.

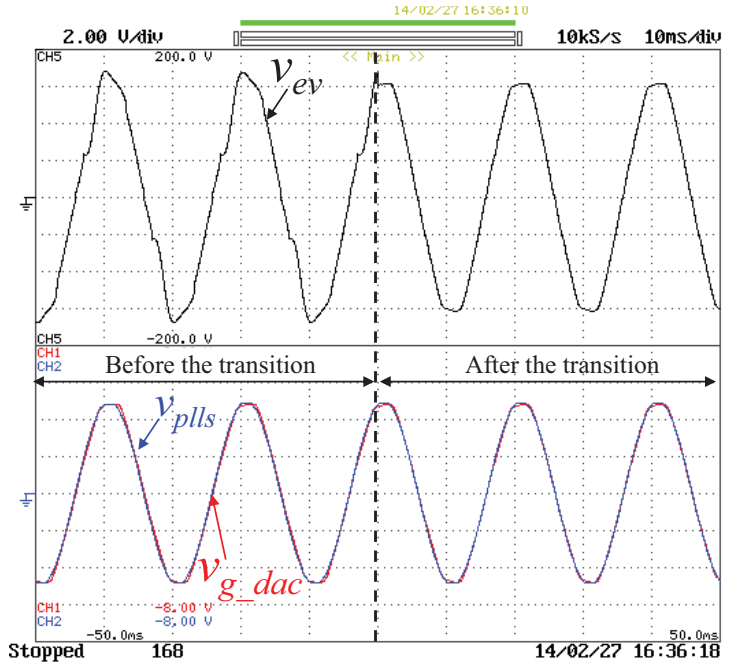

Fig. 21. Experimental results of the EV battery charger in $\mathrm{H} 2 \mathrm{~V}$ operation mode as off-line UPS: Voltage in the home electrical appliances $\left(v_{a}: 100 \mathrm{~V} /\right.$ div) and digital values of the $v_{p l l s}$ and power grid voltage $\left(v_{g_{-}}\right.$dac $)$ when the $v_{\text {plls }}$ is synchronized with the restored power grid voltage $\left(v_{g}\right)$.

were required $120 \mathrm{~ms}$. Fig. 21 shows experimental results of the EV battery charger in the $\mathrm{H} 2 \mathrm{~V}$ operation mode as off-line UPS. This figure shows the voltage in the home electrical appliances $\left(v_{a}\right)$, and also the digital values of the power grid voltage and the $v_{\text {plls }}$ signal. These results were obtained during the transition from the off-line UPS mode to the normal mode (when the voltage applied to the home electrical appliances is the power grid voltage). When the power grid voltage is restored, the angle of phase of the voltage produced by the EV in the off-line UPS operation mode is slowly synchronized with the power grid voltage. When the voltage produced by the EV is completely synchronized with the power grid voltage, the switch $s w$ is closed and the EV battery charger stops its operation as off-line UPS, i.e., the voltage applied to the home electrical appliances is again the power grid voltage. As it can be seen in Fig. 21, when the transition occurs the $v_{\text {plls }}$ is completely synchronized with the power grid voltage. It is 
important to refer that the voltage produced by the EV has a little distortion because the input passive filters are optimized for the G2V (or V2G) operation mode, and not to the V2H operation mode.

\section{CONCLUSION}

This paper describes operation modes for the electric vehicle (EV) in smart grids and smart homes. The present status of the EV operation modes basically comprehends the grid-to-vehicle (G2V) and the vehicle-to-grid (V2G), in which is exchanged power between the power grid and the EV batteries. This paper proposes two innovative smart operation modes, namely, home-to-vehicle $(\mathrm{H} 2 \mathrm{~V})$ and vehicle-for-grid (V4G). Besides these operation modes (G2V, V2G, H2V and $\mathrm{V} 4 \mathrm{G})$, an improved vehicle-to-home (V2H) is also presented in this paper framed with the other operation modes. During the $\mathrm{H} 2 \mathrm{~V}$ operation mode the current in the EV is controlled according to the current consumption of the electrical appliances in the home, aiming to prevent overloads and overcurrent trips in the main circuit breaker of the home. This operation mode is performed during the EV batteries charging or discharging processes. During the V4G operation mode the EV battery charger is used for compensating reactive power or current harmonics in the home. This operation mode can also be performed during the EV batteries charging or discharging processes. During the $\mathrm{V} 2 \mathrm{H}$ operation mode the EV is used to operate as a power source for an isolated home or as an off-line uninterruptible power supply for a grid connected home. Along the paper are presented several experimental results, both in steady-state and during transients, to validate the aforementioned operation modes and to show that the EV can represent an asset towards the smart grids and smart homes. For such purpose it was developed a $3.6 \mathrm{~kW}$ bidirectional EV battery charger prototype, which is presented and described along the paper, as well as the power theory and the voltage and current control strategies for all the operation modes.

\section{REFERENCES}

[1] Kaushik Rajashekara, "Present Status and Future Trends in Electric Vehicle Propulsion Technologies," IEEE J. Emerg. Sel. Topics Power Electron., vol.1, no.1, pp.3-10, Mar. 2013.

[2] Seshadri Srinivasa Raghavan, Alireza Khaligh, "Electrification Potential Factor: Energy-Based Value Proposition Analysis of Plug-In Hybrid Electric Vehicles," IEEE Trans. Veh. Technol., vol.61, no.3, pp.10521059, Mar. 2012.

[3] Joshua Milberg, Ann Schlenker, "Plug into the Future," IEEE Power Energy Mag., vol.9, no.1, pp.56-65, Feb. 2011.

[4] C. C. Chan, Alain Bouscayrol, Keyu Chen, "Electric, Hybrid, and FuelCell Vehicles: Architectures and Modeling," IEEE Trnas. Veh. Technol., vol.59, no.2, pp.589-598, Feb. 2010.

[5] C. C. Chan, "The State of the Art of Electric, Hybrid, and Fuel Cell Vehicles," Proc. IEEE, vol.95, no.4, pp.704-718, Apr. 2007.

[6] Deepak S. Gautam, Fariborz Musavi, Murray Edington, Wilson Eberle, William G. Dunford, “An Automotive Onboard 3.3-kW Battery Charger for PHEV Application,“IEEE Trans. Veh. Technol., vol.61, no.8, pp.3466-3474, Oct. 2012.

[7] Vítor Monteiro, Bruno Exposto, J. G. Pinto, Raul Almeida, João C. Ferreira, Andrés A. Nogueiras Meléndez, João L. Afonso, "On-Board Electric Vehicle Battery Charger with Enhanced V2H Operation Mode”,
IEEE IECON Industrial Electronics Conference, pp.1636-1642, Dallas Texas USA, Oct. 2014.

[8] Saeid Haghbin, Sonja Lundmark, Mats Alaküla, Ola Carlson, "GridConnected Integrated Battery Chargers in Vehicle Applications: Review and New Solution," IEEE Trans. Ind. Electron., vol.60, no.2, pp.459473, Feb. 2013

[9] Mohammad Ibrahim, Lionel Pichon, Laurent Bernard, Adel Razek, Jeanne Houivet, Olivier Cayol, "Advanced Modeling of a 2-kW SeriesSeries Resonating Inductive Charger for Real Electric Vehicle," IEEE Trans. Veh. Technol., vol.64, no.2, pp.421-430, Feb. 2015.

[10] J. G. Pinto, Vítor Monteiro, Henrique Gonçalves, João L. Afonso, "Onboard Reconfigurable Battery Charger for ElectricVehiclesWith Traction-to-Auxiliary Mode," IEEE Trans. Veh. Technol., vol.63, no.3, pp.1104-1116, Mar. 2014

[11] João A. Peças Lopes, Filipe Soares, Pedro M. Rocha Almeida, "Integration of Electric Vehicles in the Electric Power Systems," Proc. IEEE, vol.99, no.1, pp.168-183, Jan. 2011.

[12] Sanjaka G.Wirasingha, Ali Emdai, "Classification and Review of Control Strategies for Plug-In Hybrid Electric Vehicles," IEEE Trans. Veh. Technol., vol.60, no.1, pp.111-122, Jan. 2011.

[13] Alireza Khaligh, Zhihao Li, "Battery, Ultracapacitor, Fuel Cell, and Hybrid Energy Storage Systems for Electric, Hybrid Electric, Fuel Cell, and Plug-In Hybrid Electric Vehicles: State of the Art," IEEE Trans. Veh. Technol., vol.59, no.6, pp.2806-2814, July 2010.

[14] Ernesto Inoa, Jin Wang, "PHEV Charging Strategies for Maximized Energy Saving," IEEE Trans. Veh. Technol., vol.60, no.7, pp.29782986, Sept. 2011.

[15] A. H. Hajimiragha, C. A. Canizares, M. W. Fowler, A. Elkamel "Optimal transition to plug-in hybrid electric vehicles in Ontario, Canada, considering the electricity-grid limitations," IEEE Trans. Ind. Electon., vol.57, no.2, pp.690-701, Feb. 2010.

[16] Yonghua Song, Xia Yang, Zongxiang Lu, "Integration of Plug-in Hybrid and Electric Vehicles Experience from China," IEEE PES Power and Energy Society General Meeting, pp.1-6, July 2010.

[17] Ahmed Yousuf Saber, Ganesh Kumar Venayagamoorthy, "Plug-in Vehicles and Renewable Energy Sources for Cost and Emission Reductions," IEEE Trans. Ind. Electron., vol.58, no.4, pp.1229-1238, Apr. 2011.

[18] Jun Hua Zhao, Fushuan Wen, Zhao Yang Dong, Yusheng Xue, Kit Po Wong, "Optimal Dispatch of Electric Vehicles and Wind Power Using Enhanced Particle Swarm Optimization," IEEE Trans. Ind. Inform., vol.8, no.4, pp.889-899, Nov. 2012.

[19] Shuang Gao, K. T. Chau, Chunhua Liu, Diyun Wu, C. C. Chan, "Integrated Energy Management of Plug-in Electric Vehicles in Power Grid With Renewables," IEEE Trans. Veh. Technol., vol.63, no.7, pp.3019-3027, Sept. 2014.

[20] Tian Zhang, Wei Chen, Zhu Han, Zhigang Cao, "Charging Scheduling of Electric VehiclesWith Local Renewable Energy Under Uncertain Electric Vehicle Arrival and Grid Power Price," IEEE Trans. Veh. Technol., vol.63., no.6, pp.2600-2612, July 2014.

[21] Willett Kempton, Jasna Tomic, "Vehicle-to-grid Power Fundamentals: Calculating Capacity and Net Revenue," ELSEVIER Journal of Power Sources, vol.144, no.1, pp.269-279, June 2005.

[22] Murat Yilmaz, Philip T. Krein, "Review of the Impact of Vehicle-toGrid Technologies on Distribution Systems and Utility Interfaces," IEEE Trans. Power Electron., vol.28, no.12, pp.5673-5689, Dec. 2013.

[23] Willett Kempton, Jasna Tomic, "Vehicle-to-Grid Power Implementation: From Stabilizing the Grid to Supporting Large-Scale Renewable Energy," ELSEVIER Journal of Power Sources, vol.144, pp.280-294, Apr. 2015.

[24] Bill Kramer, Sudipta Chakraborty, Benjamin Kroposki, "A review of plug-in vehicles and vehicle-to-grid capability," IEEE IECON Industrial Electronics Conference, pp.2278-2283, Nov. 2008.

[25] Chengke Zhou, Kejun Qian, Malcolm Allan, Wenjun Zhou, "Modeling of the Cost of EV BatteryWear Due to V2G Application in Power Systems," IEEE Trans. Energy Convers., vol.26, no.4, pp.1041-1050, Dec. 2011. 
[26] José Joaquín Escudero-Garzás, Ana García-Armada, Gonzalo SecoGranados, "Fair Design of Plug-in Electric Vehicles Aggregator for V2G Regulation," IEEE Trans. Veh. Technol., vol.61, no.8, pp.34063419, Oct 2012 .

[27] Vítor Monteiro, J. G. Pinto, Bruno Exposto, João C. Ferreira, João L. Afonso, "Smart Charging Management for Electric Vehicle Battery Chargers," IEEE VPPC Vehicle Power and Propulsion Conference, pp.1-5, Oct. 2014.

[28] Mithat C. Kisacikoglu, Burak Ozpineci, LeonM. Tolbert, "EV/PHEV Bidirectional Charger Assessment for V2G Reactive Power Operation," IEEE Trans. Power Electron., vol.28, no.12, pp.5717-5727, Dec. 2013.

[29] Vítor Monteiro, J. G. Pinto, Bruno Exposto, João C. Ferreira, Carlos Couto, João L. Afonso, "Assessment of a Battery Charger for Electric Vehicles with Reactive Power Control," IEEE IECON Industrial Electronics Society, Montréal-Canada, pp.5124-5129, Oct. 2012.

[30] Mithat C. Kisacikoglu, Metin Kesler, Leon M. Tolbert, "Single-Phase On-Board Bidirectional PEV Charger for V2G Reactive Power Operation," IEEE Trans. Smart Grid, vol.6, no.2, pp. 767-775, Mar. 2015.

[31] Vehbi C. Gungor, Dilan Sahin, Taskin Kocak, Salih Ergut, Concettina Buccella, Carlo Cecati, Gerhard P. Hancke, "Smart Grid and Smart Homes - Key Players and Pilot Projects," IEEE Ind. Electron. Mag., vol.6, pp.18-34, Dec. 2012.

[32] Chunhua Liu, K. T. Chau, Diyun Wu, Shuang Gao, "Opportunities and Challenges of Vehicle-to-Home, Vehicle-to-Vehicle, and Vehicle-toGrid Technologies," Proc. IEEE, vol.101, no.11, pp.2409-2427, Nov. 2013.

[33] Chenrui Jin, Jian Tang, Prasanta Ghosh, "Optimizing Electric Vehicle Charging: A Customer's Perspective,” IEEE Trans. Veh. Technol., vol.62, no.7, pp.2919-2927, Sept. 2013

[34] Marc Multin, Florian Allerding, Hartmut Schmeck, "Integration of Electric Vehicles in Smart Homes - An ICT-based Solution for V2G Scenarios," IEEE PES ISGT Innovative Smart Grid Technologies, pp.18, Jan. 2012.

[35] J. G. Pinto, Vítor Monteiro, Henrique Gonçalves, Bruno Exposto, Delfim Pedrosa, Carlos Couto, João L. Afonso, "Bidirectional Battery Charger with Grid-to-Vehicle, Vehicle-to-Grid and Vehicle-to-Home Technologies," IEEE IECON Industrial Electronics Conference, pp.5934-5939, Vienna Austria, Nov. 2013.

[36] Vehbi C. Güngör, Dilan Sahin, Taskin Kocak, Salih Ergüt, Concettina Buccella, Carlo Cecati, Gerhard P. Hancke, "Smart Grid Technologies: Communication Technologies and Standards," IEEE Trans. Ind. Informat., vol.7, no.4, pp.529-539, Nov. 2011.

[37] João C. Ferreira, Vitor Monteiro, João L. Afonso, "Vehicle-to-Anything Application (V2Anything App) for Electric Vehicles," IEEE Trans. Ind. Informat., vol.10, no.3, pp.1927-1937, Aug. 2014.

[38] CEiiA and University of Minho, "MobiCar - Design, development, testing and demonstration of sustainable mobility solutions - PPS4 MOBICarPower - Development of powertrain architectures for electrical systems," Reference: AAC n.o 36/SI/2009 - 13844. (July 2015) [online] Available: http://www.ceiia.com/mobility_device/.

[39] Masoud Karimi-Ghartemani, "Linear and Pseudolinear Enhanced Phased-Locked Loop (EPLL) Structures," IEEE Trans. Ind. Electron., vol.61, no.3, pp.1464-1474, Mar. 2014.

[40] José Rodríguez, Jorge Pontt, César A. Silva, Pablo Correa, Pablo Lezana, Patricio Cortés, Ulrich Ammann, "Predictive Current Control of a Voltage Source Inverter," IEEE Trans. Ind. Electron., vol.54, no.1, pp.495-503, Feb. 2007.

[41] Ala Al-Haj Hussein, Issa Batarseh, "A Review of Charging Algorithms for Nickel and Lithium Battery Chargers,” IEEE Trans. Veh. Technol., vol.60, no.3, pp.830-838, Mar. 2011.

[42] J. Martins, F. P. Brito, D. Pedrosa, Vítor Monteiro, João L. Afonso, "Real-Life Comparison between Diesel and Electric Car Energy Consumption," in Grid Electrified Vehicles: Performance, Design and Environmental Impacts, 1st ed., Carla Alexandra Monteiro da Silva, Ed. Nova Science Publishers, 2013, Chapter 10, pp.209-232.

[43] Antonio Moschitta, Paolo Carbone, Carlo Muscas, "Performance Comparison of Advanced Techniques for Voltage Dip Detection," IEEE Trans. Instrum. Meas., vol.61, no.5, pp.1494-1502, May 2002.

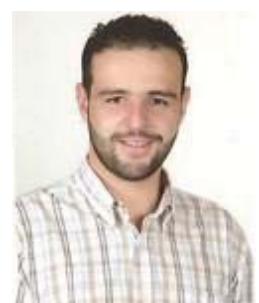

Vítor Monteiro (S'10) was born in Guimarães, Portugal, in May of 1984. He received the M.Sc. degree in industrial electronics and computer engineering from the University of Minho, Guimarães, in 2012. He is currently working toward the Ph.D. degree with the University of Minho. Since 2008, he has been a member of the Group of Energy and Power Electronics (GEPE) and a collaborator with Centro Algoritmi, University of Minho. His research interests include power electronic converters, digital control techniques, smart grids, and electric vehicles. Mr. Monteiro received a Doctoral Scholarship from the Foundation for Science and Technology of Portugal.

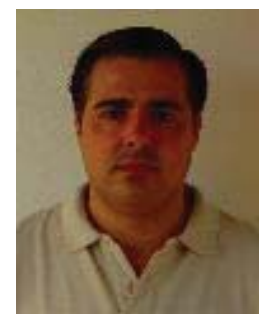

J. G. Pinto (S'06) was born in Guimarães, Portugal, in 1977. He received the B.Sc. degree in Electronics Engineering and the M.Sc. degree in Industrial Electronics from the University of Minho, Portugal, in 2001 and 2004, respectively. From 2002 to 2006 worked as invited Assistant Lecturer at the Electrical Department of the Polytechnic Institute of Bragança, Portugal. From 2006 to 2012 he worked as a researcher at the Group of Energy and Power Electronics (GEPE) of the Centro Algoritmi, at the University of Minho. He received the $\mathrm{PhD}$ degree in Electronics and Computer Engineering from the University of Minho, in 2012. Since 2013 he works as invited Assistant Professor at the Industrial Electronics Department of the University of Minho. His research interests are related with Power Electronics, Power Quality and Digital Control of Power Converters

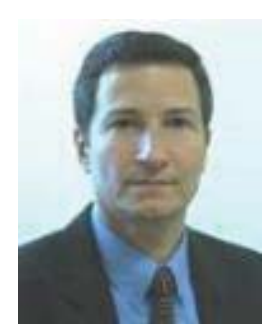

João Luiz Afonso (M'00) was born in Rio de Janeiro, Brazil, in 1963. He received the B.S. and M.Sc. degrees in Electrical Engineering from the Federal University of Rio de Janeiro in 1986 and 1991, respectively, and the $\mathrm{Ph} . \mathrm{D}$. degree in Industrial Electronics from the University of Minho, Guimarães, Portugal, in 2000. Since 1993, he has been with the Department of Industrial Electronics, University of Minho, where he is Associate Professor. He teaches Electrical Machines, Electrical Energy Systems, Complements of Power Electronics, Electrical Power Quality, Active Power Filters and Renewable Energy. He is a researcher with the Group of Energy and Power Electronics (GEPE), and he coordinates the thematic strand of Sustainable and Smart Cities of the Centro Algoritmi. His research interests include: Power Quality, Active Power Filters, Renewable Energy, Electric Vehicles, Energy Efficiency, Energy Storage Systems, Smart Grids and Smart Cities. 